\title{
The German locative-directional alternation
}

\section{A Peeling account}

\section{Pavel Caha}

Received: 10 August 2008 / Accepted: 9 February 2009 / Published online: 1 October 2010

(C) The Author(s) 2010. This article is published with open access at Springerlink.com

\begin{abstract}
I investigate the locative-directional alternation in German, expressed by the change of case on the complement of a preposition, and its consequences for the theory of case in general. I argue that oblique cases and structural cases are assigned in a uniform manner, but they are distinct in the amount of functional structure: oblique case contains structural case. Following Starke (2005), I claim that oblique cases can be promoted to structural cases by stranding layers of oblique case.
\end{abstract}

Keywords Case $\cdot$ Passive $\cdot$ Peeling $\cdot$ Prepositional phrases

\section{Introduction}

Consider the alternation in case observed in (1). In the first example (1a), the preposition in 'in' assigns dative to its complement, and the interpretation of the PP is locative. In (1b), the same preposition assigns accusative, which leads to the directional interpretation of the PP. ${ }^{1}$

(1) The locative-directional alternation in German: DAT $\rightarrow$ ACC

a. Alex tanzte in dem Zimmer.

Alex danced in the.DAT room

'Alex danced in the room.'

(Zwarts 2006, ex. 2a)

\footnotetext{
${ }^{1}$ Non-English examples are German, unless indicated otherwise.

P. Caha $(\otimes)$

CASTL, University of Troms $\varnothing, 9037$ Troms $\varnothing$, Norway

e-mail: pavel.caha@hum.uit.no
} 
b. Alex tanzte in das Zimmer.

Alex danced in the.Acc room

'Alex danced into the room.'

(Zwarts 2006, ex. 2b)

Here I argue that the case alternation is to be taken at face value: as a change of an oblique case to a structural case. This is something that has been often argued to be unattested, and what various theories of case try to make theoretically impossible (see, e.g., the recent discussion in Woolford 2006, or Marantz 1991 from a different perspective). One of the main empirical findings feeding into such a theory is the (apparent) failure of dative arguments to change to nominative in passive. Such theories, however, predict that one of $(1 \mathrm{a}, \mathrm{b})$ must be ungrammatical, a prediction which is not borne out. I aim to develop a theory of the case alternation in (1), which will allow for oblique case/structural case alternations, but which will also be able to account for the failure of such alternations where this is needed.

The organization of the paper is as follows. In Section 2, I provide an overview of the systematic nature of the locative-directional alternation. In Section 3, I discuss a recent account of the alternation by den Dikken (2003, 2010) together with some of its drawbacks. In Section 4, I outline a theory according to which the structure in (1a) (with dative case) is the input for deriving (1b) (with accusative case). This means that (1b) involves (i) multiple case assignment (against, for instance, Chomsky 1998), and (ii) an alternation between an oblique case and a structural case (against, for instance, Woolford 2006).

In Sections 5 and 6, I show evidence that both dative and accusative are checked under overt movement. This feeds into an account of (1) in terms of the Peeling theory of Case (Starke 2005), in Section 8. According to this theory, DPs are base-generated with a number of case-related functional heads on top of them, and they strand these heads under movement. Specifically, I build on the proposal of Bayer et al. (2001), that oblique case (KP) syntactically contains structural case (DP), and I will claim that the dative in (1a) changes to accusative in (1b) by a sub-extraction of the accusative DP from within the dative KP. Within the proposed theory, I outline an analysis of accusative and dative passives in Section 9. Section 10 concludes.

\section{Cross-linguistic stability of the locative-directional alternation}

The alternation in (1) is not restricted to a single German preposition. In fact, it is quite common in German that prepositions assign either dative or accusative to their complement, giving rise to a locative or directional interpretation, respectively (see Zwarts 2006 for a list of adpositions). A similar phenomenon occurs elsewhere in Germanic (Icelandic), and can further be found in the majority of Slavic languages, in Romance (Latin), in Ancient Greek and in Classical Armenian. In Table 1, I give a brief overview of the situation in IndoEuropean. 
Table 1 Examples of alternating adpositions

\begin{tabular}{lllll}
\hline Language & Adposition & Location & Goal & \\
\hline Classical Armenian & $i$ 'in' & LOC & ACC & Schmitt (1981) \\
Ancient Greek & para 'at' & DAT & ACC & Smyth (1974) \\
Czech & pod 'under' & INS & ACC & Emonds (2007) \\
& na 'on' & LOC & ACC & Emonds (2007) \\
Icelandic & $i$ 'in' & DAT & ACC & Svenonius (2002) \\
Latin & in 'in' & ABL & ACC & Hale and Buck (1903) \\
\hline
\end{tabular}

The table shows that the directional variant of an alternating adposition assigns accusative, while the locative version leads to an oblique case. The oblique is (superficially) distinct from language to language, and sometimes even within a language (Czech); however, the association of accusative with the directional interpretation is fairly robust. This suggests that the alternation illustrated in (1) is neither a quirk of the adposition in, nor of German, but that we are looking at a phenomenon that has recurrent properties across languages (Indo-European, at least). I state the relevant generalization explicitly in (2).

(2) The Law of the Locative-Directional Alternation: For alternating adpositions, locative interpretation is associated with an oblique case, directional interpretation with accusative.

Given (2), it is justified to regard the alternation not as a matter of lexical stipulation, but as a general phenomenon that can shed some light on the syntax of spatial PPs and case in general. However, the trouble for any analysis begins with the realization that the data are not as neat as Table 1 suggests. Apart from the core pattern (which surely needs to be accounted for), there are sub-(ir)regularities: not all adpositions alternate, there are directional adpositions with obliques, and also locative adpositions which take accusative. The test-ground for comparing analyses is large to begin with; in order to keep it to a manageable size, I am going to focus only on adpositional phrases with single, morphologically simplex, and spatial or temporal adpositions.

\section{What are the main theoretical challenges?}

In this section, I first sketch the bare bones of an account proposed by den Dikken (2010), which, as it stands, accounts for the generalization in (2). Subsequently, I discuss challenges his (and any other) analysis meets when more data are taken into the picture.

\section{1 den Dikken $(2003,2010)$}

Den Dikken (2003, 2010), focussing on Dutch and German (and building on Koopman 2000), proposes that the structure of adpositional phrases is quite fine-grained. The maximal functional sequence $\left(f_{s e q}\right)$ comprises two main 
bits: the locative part and the directional part, where the latter embeds the former (see also van Riemsdijk 1978; Jackendoff 1983; van Riemsdijk and Huybregts 2002; Svenonius 2010b). Details of the analysis aside, the intuition is that both locative and directional prepositions are lexical heads, each dominated by a series of (maximally) three functional heads, labeled Asp (for Aspect), Deix (for deixis), and C (for complementizer). Case is assigned by the aspectual heads: oblique case by Asp-loc, accusative by Asp-dir. ${ }^{2}$

$$
\underset{\text { ACC }}{[C-d i r}[\text { Deix-dir }[\mathbf{A s p}-\mathbf{d i r}[\mathrm{P}-\operatorname{dir}[\mathrm{C}-\mathrm{loc}[\mathrm{Deix}-\mathrm{loc}[\mathbf{\mathrm { Asp } - l o c}[\mathrm{P}-\mathrm{loc}[\mathrm{DP}
$$

The proposal immediately yields (2) as a consequence: oblique case is freely available in locative PPs, while accusative is dependent on the directional interpretation, since the locus of its assignment is Asp-dir. What is crucial is that case in PPs is dissociated from the lexical item itself, and associated with a particular functional projection in the adpositional fseq. This allows for a sufficiently general connection between an oblique case and the locative interpretation on the one hand, and accusative case and the directional interpretation on the other. However, if one were to link a particular case to a particular adposition by lexical stipulation, the Law of the Locative-Directional Alternation would be unaccounted for.

Despite the success of the theory to capture the main descriptive generalization, there are some aspects of the analysis that I want to look at in more detail. In the reminder of this section, I point out two issues that arise.

\subsection{The Missing Assigner problem}

The first stumbling block we encounter is the apparent necessity to put together the proposed account with what I call Uniqueness of Case Assignment:

(4) Uniqueness of Case Assignment: DPs receive exactly one case in the course of a derivation. ${ }^{3}$

What Uniqueness of Case Assignment amounts to for the analysis sketched above, is the necessity for Asp-loc to be missing in the directional version of the alternating adpositions, e.g., in (1b). The reason is that if P-dir in (1b) (silent in den Dikken's analysis) took as a complement a constituent equal

\footnotetext{
${ }^{2}$ I leave aside the question of the parametrization of the assignment of a particular oblique.

${ }^{3}$ In recent minimalist approaches emanating from Chomsky (1998), the Uniqueness of Case Assignment is subsumed under a broader condition, the so-called Activity Condition. I will end up rejecting this condition. The purpose of bringing it up is to highlight the problems it leads to in the context of den Dikken's analysis.
} 
to or larger than Asp-loc, Asp-loc would also be the closest case assigning head, and that would incorrectly lead to the emergence of dative case in the directional reading of an alternating adposition. ${ }^{4}$ Hence, Asp-loc must be missing in exactly those instances where accusative takes over.

The absence of Asp-loc in (1b) is implemented in den Dikken (2003:29) via the requirement that the silent $\mathrm{P}$-dir must be licensed by (covert) incorporation of the overt P-loc. Then, granted the assumption that the lexical P-loc can move to the lexical P-dir only if it does not move via an intermediate functional projection, Asp-loc will always be missing when P-dir is silent.

A point of critique has been put forth by Zwarts (2006). Zwarts notes that the locative and directional version of an alternating adposition should differ semantically, since the directional version lacks the semantic information contributed by the dative assigner (Asp-loc). Zwarts' point is then that they don't, or at least not obviously so. However, it is necessary to add that Zwarts (2006) comments on an earlier version of den Dikken (2010), where several aspects of implementation were different (see also den Dikken 2010, ftn.29). As far as I can see, however, the general problem still holds, and I call it the Missing Assigner problem: there is no evidence that the semantic contribution of the dative assigner is absent, even though the Uniqueness of Case Assignment predicts it.

Given the problem we encounter when trying to reconcile the approach with Uniqueness of Case Assignment, it is worth considering an alternative which abandons it and allows the DP to pass through two case positions (lower Asploc, and higher Asp-dir), leading to multiple case assignment (see e.g., Bejar and Massam 1999; Merchant 2006; Pesetsky 2007; Richards 2007). Under such an approach, which I will adopt here, dative is assigned in both locative and directional PPs, but it gets 'overridden' in directional versions of alternating adpositions due to a further assignment of accusative from Asp-dir. Now we need not care about how to fine-tune the presence or absence of Asp-loc depending on other material merged later on; the right case is determined only by the presence/absence of Asp-dir, correlating with the presence/absence of directional interpretation.

\subsection{The Case Preservation problem}

Nothing else said, however, the alternative solution leads to overgeneralization. For instance, the adposition $z u$ 'to' assigns dative (see (5)), even though it is interpreted as directional. For reasons which are internal to den Dikken's analysis, it is necessary that Asp-dir is present with $z u$, and

\footnotetext{
${ }^{4}$ Here and elsewhere, I assume that a potential case assigner cannot be skipped, an assumption related to a general notion of locality of syntactic operations.
} 
hence, we would expect accusative..$^{5}$ I call the inability of Asp-dir to 'override' the dative the Case Preservation problem.

$$
\begin{aligned}
& \text { Er rannte zu-m Park. } \\
& \text { he ran to-the.DAT park } \\
& \text { 'He ran to the park.' }
\end{aligned}
$$

(Zwarts 2005, ex. 6b)

In den Dikken's theory, such a type of a PP receives an analysis in which the directional $z u$ 'to' is hosted by P-dir (thus capturing the directional charachter of $z u$ ), and selects for a complement with a silent P-loc as a lexical head. $Z u$ also determines the size of the complement by subcategorization, so that it includes the dative assigning Asp-loc. With dative case already assigned when the derivation reaches the directional part of the fseq, the presence of Asp-dir will play no role in case assignment. That is because once the case of the DP has been fixed to dative, it is immune to further case licensors by (4).

The problem with such a solution is the silent P-loc selected by $z u$ 'to'. The reason is that there is no way of syntactically restricting its distribution (den Dikken's conclusion). First, we cannot require that this adposition incorporate into the overt P-dir $(z u)$. In order for that to be possible, Asp-loc would have to be missing. But given the dative in (5), this cannot be so. Incorporation from below is not an option either. Lexical P-loc can be incorporated into only by a lexical head, the noun. And for that to happen, there must be no functional head between $\mathrm{N}$ and $\mathrm{P}-\mathrm{loc}$, which is not the case.

And so nothing else said, the system leads to two false predictions, both connected to the unlicensed P-loc. The first prediction is that the silent P-loc can also be used outside of directional contexts, which means that a bare dative should express location; and that is not the case. The second prediction is that $z u$ 'to' should combine with locative PPs headed by an overt adposition, which is not the case either (6).

$$
\begin{aligned}
& \text { *Er geht }\{\mathrm{zu}\} \text { in }\{\mathrm{zu}\} \text { dem / den Laden }\{\mathrm{zu}\} \\
& \text { he walks to in to the.DAT / the.Acc store to } \\
& \text { 'He walks into the store.' } \\
& \text { (Noonan 2007, exs. 12a-c) }
\end{aligned}
$$

These two problems are related, and they could both be fixed if we required that $z u$ 'TO AT' spells out both P-dir (TO) and P-loc (AT). Not only do we get

\footnotetext{
${ }^{5}$ If Asp-dir was absent, we would be left only with P-dir. Such a configuration, however, necessarily leads to the incorporation of P-dir (i.e., $z u$ ) to the verb. Given that $z u$ does not incorporate, it has to involve Asp-dir.

A reviewer reminds me that it still can be the case that there is no Asp-dir in (5). One would have to say that $z u$ 'to' is a locative adposition embedded under a silent P-dir, which, if it incorporates into a verb, can lack Asp-dir. It seems to me that this approach raises more problems than it solves; the most pressing issue being why all locative PPs cannot be rendered directional by virtue of this silent P-dir.
} 
rid of the silent P-loc, there would also be no expectation that there is going to be another P-loc present. The solution would be quite natural: $z u$ 'to' acts as a directional counterpart of bei 'at' (see Noonan 2007; Caha 2007a; Zwarts 2008). However, this fix is unavailable; any solution which would allow the silent P-loc to get 'connected' with P-dir $(z u)$ across Asp-loc, will also allow a similar connection between the silent P-dir and overt P-loc with alternating adpositions, weakening the initial account of (1b).

Leaving den Dikken's analysis at this point, it is fair to note that the alternative approach seems to fare even worse for (5), since it is unclear why accusative would be unable to override the dative assigned lower down, given that such an overriding was exactly the thing which was supposed to give us an account of the case alternation.

Put generally, it seems that the Missing Assigner problem and the Case Preservation problem point in opposite directions. With Uniqueness of Case Assignment, we can understand why there is no accusative in (5). However, a set of assumptions is needed for the alternation to fall in place, which ultimately leads to empirical problems. In a theory where multiple case assignment is allowed, we deal with the alternation in an elegant way, but the problem of Case Preservation is harder to tackle.

\subsection{A way out?}

At this point, it is worth side-stepping the theoretical issues to ask the question whether dative-assigning directional adpositions share some other property that sets them aside, and whether that property can be somehow linked to their behavior in the domain of case. Apart from $z u$ 'to', there are three more directional adpositions that assign dative in German: nach 'to', aus 'out of' and von 'from'. ${ }^{6}$ The generalization, inspired by Zwarts (2006), is that all of the

\footnotetext{
${ }^{6}$ Zwarts (2006) adds entgegen 'against' to the list; however, Gehrke (2008:131) points out that entgegen 'against' does not have a spatial reading as a preposition. No matter whether entgegen 'against' is included in the set of adpositions or not, this does not change the emerging generalization.

A reviewer points out that it is hard to say what case nach 'to' assigns as a spatial adposition, since it only combines with article-less DPs, and these in turn do not show the accusative/dative distinction on their sleeve. The reviewer notes that the classification of nach 'to' as a dative assigner is based on its properties in temporal domain, where it demonstrably assigns dative. Also (set) phrases like nach Haus-e 'to home-dat' (where the noun has kept an archaic dative ending lost elsewhere) suggest that this is indeed the case. In this connection, Henk van Riemsdijk (p.c.) has pointed out to me that nach also takes a visible dative in its meaning of according to:
}

(i) mein-er Meinung nach my-DAT opinion according to 'according to my opinion'

(Henk van Riemsdijk, p.c.) 
directional adpositions which assign dative are strictly directional. That means that they cannot be used to express location: ${ }^{7,8}$

The Case Preservation Generalization (German): If a directional adposition assigns dative, it is strictly directional.

It seems that no matter what theoretical alternative we choose, there does not seem to be a straightforward way to understand (7). I now proceed to develop an approach to the alternation in which DPs can pass through multiple case positions in a single derivation, and make (7) fall out from the analysis.

\section{The account in a nutshell}

I start with the derivation of a locative PP in German. This derivation also represents a preliminary step for the derivation of directional adpositions, which will be conceptualized as an extension of the locative PP. First we merge the P-loc with the Ground argument (8a). Then the Ground moves to the dative assigning position Asp-loc (8b). I think of this position as the PP equivalent of the structural object position in VPs. I propose that this position is fairly high up in the structure, higher than, for instance, the base-generated position of the measure phrase, differing from den Dikken on this point.

In German, locative adpositions are prepositions, and so the DP movement is followed by a step of remnant movement of the P-locP (8c), forming an XP. I do not discuss an alternative involving head-movement. I also leave for future research the identity of $\mathrm{X}$, and the motivation for the movement. The remnant movement completes the derivation of a locative PP.

$$
\begin{aligned}
& \text { Derivation of locative PPs } \\
& \text { a. [ P-loc DP ] } \\
& \rightarrow \text { Merge Asp-loc, move DP to its Spec } \\
& \text { b. [DP-dat Asp-loc ... [ P-loc DP ] ] } \\
& \rightarrow \text { remnant movement of P-locP } \\
& \text { c. }\left[{ }_{X P}[\mathrm{P}-\mathrm{loc} \mathrm{DP}] \ldots[\mathrm{DP}-\mathrm{dat} \text { Asp-loc ... }]\right]
\end{aligned}
$$

\footnotetext{
${ }^{7}$ A similar insight is offered by Gehrke (2007:109): “[D]ative appears with all locatives and all those adpositions which are unambiguously source and goal."

${ }^{8} \mathrm{An}$ anonymous reviewer points out that $z u$ can be used as a locative adposition in a set expression $z u$ Hause 'at home'. Henk van Riemsdijk (p.c.) notes in addition that $z u$ has a locative meaning in some temporal uses:
}

(i)

$$
\begin{aligned}
& \text { zu-r richtigen Zeit } \\
& \text { to-DAT right time } \\
& \text { 'in the right moment' }
\end{aligned}
$$

(Henk van Riemsdijk, p.c.)

I set these examples aside for now together with another 'locative' use of zu: Universität zu Berlin 'University of Berlin.' I come back to these examples in Section 8.3. 
In directional PPs, German offers two options. I start by alternating prepositions. The input for the derivation is the locative PP (8c). This structure is augmented by a head I call Path. This head has the potential to attract a DP to its Spec and make it accusative. Consequently, the dative DP leaves its position and moves to Spec,PathP, see (9a). In this step, the dative changes to accusative. This is once again followed by a remnant P-locP movement, which restores the original order. I assume-and comment on later-that in German, this movement pied-pipes the whole XP. As before, motivation for this movement and its head movement alternative are avenues for future research (but see footnote 11).

Derivation of alternating directional PPs

$\rightarrow$ Take locative PP (=XP), add Path, move DP to its Spec

a. DP-dat-acc Path $\left[X_{P}[\mathrm{P}-\right.$ loc DP $] \ldots$... DP-dat Asp-loc ... ] ]

$\rightarrow$ remnant movement of the XP

b. $[X P[\mathrm{P}-$ loc DP $] \ldots$ Asp-loc ...] ... [ DP-acc [ Path t-XP ] $]$

The rationale behind this complex derivation is to avoid the Missing Assigner problem; the semantic contribution of Asp-loc is now present in both locatives and directionals. Further, the emergence of accusative is controlled for solely by Path: no assumptions are needed to make Asp-loc disappear in (9b). This derivation instantiates the theoretical option I explore in this paper: multiple case checking.

Let me now proceed to the proposal for adpositions like $z u$ 'to'. We again start from (8c) (the locative PP) by adding Path (10a). $\mathrm{Zu}$ 'TO AT' lexicalizes a stretch of heads (a constituent, as I argue later), notably the Path head TO and the P-loc 'AT', which are put in bold in (10a). (I come back to details of lexicalization in Section 8.3.) This proposal avoids the troublesome silent Ploc, at the same time capturing the directional character of $z u$ and the fact that it does not combine with locative PPs.

One could imagine that the derivation will now continue by movement of the DP to Spec,PathP as we saw above, and as depicted in (10b).

Derivation of some strictly directional Ps

$\rightarrow$ Take locative PP $(=\mathrm{XP})$, add Path

a. Path [ [ P-loc DP ] ... [ DP-dat Asp-loc ... ] ]

$\rightarrow$ DP moves to the accusative position

b. *DP-dat-acc Path [ [ P-loc DP ] ... [ DP dat Asp-loc ... ] ]

Such a movement, however, would lead to the emergence of accusative, and so it needs to be blocked. I propose that this is due to a condition similar to the Doubly Filled COMP Filter, but quite general. Such a condition has been proposed by Koopman (1996) and Starke (2004); the latter states this as (11). The condition has the effect of rendering (10b) illicit. The derivation of the 
directional PP thus terminates as (10a); this happens just in case the Path head is lexicalized by a strictly directional adposition. ${ }^{9}$

Doubly Filled Nothing (Starke 2004): No projection can have both its head-terminal and its specifier present at the same time.

To sum up: I propose that both dative and accusative are checked under overt movement to a designated specifier. In directional PPs with accusative, dative is checked first, and accusative is checked later on. The checking of accusative is sometimes impossible due to the Doubly Filled Nothing condition, which forces the DP to stay in the dative position. This explanation of the Case Preservation problem relies on the observation that only strictly directional prepositions (which lexicalize Path) govern dative in Goal PPs.

This implementation avoids the problems den Dikken's analysis faces: we have eliminated the silent P-loc, and we have also made it possible for the directional PP to be built literally on top of the locative PP, including the dative assigner. Apart from this theoretical advance, I now turn to empirical evidence which independently supports these derivations. In Section 5, I give reasons to think that dative is checked by overt movement. In Section 6, I discuss data from Dutch which support the derivations arrived at for the directional PPs.

\section{The nature of the dative}

Regarding the nature of the dative case in prepositional PPs in German, there are two broad approaches. The first option is that the dative is assigned in the Spec of a designated projection, as in den Dikken (2010), or as here. (The first option further branches: either we have overt movement (as here), or the DP stays in situ in overt syntax (den Dikken), and checks case covertly.) The second option is that the dative is a default case, as recently advocated by van Riemsdijk (2007) and adopted also in Gehrke (2008).

The point of going into this discussion bears on the whole issue of multiple case assignment. If the dative is a default case, it is not 'assigned' to the Ground

\footnotetext{
${ }^{9}$ The proposal suggests that there is no DP movement across the Path head, when Path is lexicalized by a strictly directional adposition. This seems to run counter to certain non-spatial examples with postpositional nach 'to' (see footnote 6), but also some spatial PPs (brought to my attention by Henk van Riemsdijk, p.c.):
}

(i)

$$
\begin{aligned}
& \text { mir entgegen } \\
& \text { I-DAT towards } \\
& \text { 'towards me' }
\end{aligned}
$$

(Henk van Riemsdijk, p.c.)

I come back to these examples in Section 8.3, where I suggest that it is not the DP which moves, but a larger category, and the DP is carried along inside it. Recall though that Gehrke (2008:131) proposes an alternative analysis of spatial entgegen, namely as a separable verbal prefix, rather than a postposition. 
argument in syntax, but it is a way German deals with a DP that lacks case. In such a case, the accusative in directional PPs would not be a reflex of a second case position, and the alternation can be incorporated into a version of case theory where DPs are case-marked only once. The plan is as follows: I first review the proposal by van Riemsdijk (2007), and then I discuss data which point to the conclusion that dative is assigned under overt movement to a designated Spec.

\subsection{Van Riemsdijk (2007)}

Van Riemsdijk (2007) develops a theory of case marking in German PPs which is similar to the present one in several respects. The core of the approach is the proposal that accusative case in German PPs expressing a Route (as in (12a)), is the same accusative that one sees on measure phrases (as in (12b)). ${ }^{10}$ The plausibility of such a proposal is supported by a number of criteria adduced by van Riemsdijk. Consider, for instance, the fact that certain modifiers prototypically associated with measure phrases, such as the adjectives 'half' and 'whole', also combine with the phrase den Berg in (12a). As (12c) shows, this is not trivial; it is not always the case that an accusative DP is eligible for such a modification.
a. Er ist den \{halben/ganzen\} Berg hinauf gegangen. he has the.Acc half / whole mountain up gone 'He went up half the mountain / the whole mountain.'
b. Er hat die \{halbe/ganze\} Nacht geschlafen. he has the.Acc half / whole night slept 'He slept half the night / all night.'
c. *Er ist auf den \{halben/ganzen\} Berg hinauf he has onto the.Acc half / whole mountain up gegangen.
gone

'He has gone up onto half the mountain / the whole mountain.'

(van Riemsdijk 2007, exs. 10a,b,d)

Van Riemsdijk encodes the connection between the accusative and the measure phrase properties by proposing that they are due to a single head: Route. This head, see (13), (i) takes the locative PlaceP as a complement, (ii) imposes a measure interpretation on its object, and (iii) assigns accusative to its Spec under Spec,Head agreement. Thus, a DP like the one in (12a) moves overtly to Spec, RouteP.

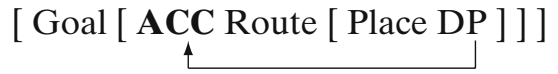

\footnotetext{
${ }^{10}$ The notion of Route is meant to cover "motion/orientation/path/route," as opposed to static location on the one hand, and goal/source path on the other.
} 
To extend the proposal to the locative-directional alternation, van Riemsdijk suggests the following. First, dative is a default case. From this, it follows that as long as the Ground does not move to the accusative position, it surfaces in dative, which in turn accounts for the lack of accusative in locatives. When it comes to Goal-directional PPs, they are argued to be built on top of the RouteP by the addition of a Goal head, see (13), and so they too contain the accusative position.

The proposal shares aspects with the one put forth here. First, there is a dedicated accusative position to which DPs move overtly. Second, the prepositional order in German directional PPs is achieved by movement of the preposition to the left of the raised DP (to Goal). ${ }^{11}$ And third, if a DP does not move to the higher accusative position, it surfaces in dative.

The difference between the proposals I want to focus on is the way the dative emerges in locative PPs. Whereas van Riemsdijk (2007) proposes that it is a default case, I claim (as does den Dikken) that it is assigned by a dedicated head. I depart from den Dikken, however, in proposing that the Ground moves overtly to the Spec of this head (at least in German).

\subsection{Raising to dative in PPs}

The argument comes from a connection between the spatial and temporal domain in German, namely the homophony between spatial 'in front of' (14a) and temporal 'before' (14b), both vor.
a. vor dem Haus in front the.DAT house
b. Die Dinosaurier sind vor der Eiszeit ausgestorben. the dinosaurs are before the.DAT ice age died out 'The dinosaurs died out before the ice age.'

(Haspelmath 1997, ex.10a)

A possible interpretation of the pattern in (14) is that the adposition vor 'in front of' is syntactically and semantically identical to vor 'before'. The possibility for vor to be used in both contexts would then be due to the fact that space and time are (cognitively) structured in similar ways. ${ }^{12}$ Under such an interpretation, vor in (14a) locates the Figure along an axis projected from the center of the house through its front. ${ }^{13}$ In (14b), the same preposition does the same job; it locates a Figure (dinosaurs' dying out) on the (time-)axis projected

\footnotetext{
${ }^{11}$ In van Riemsdijk (2007) this is achieved by head-movement, whereas here I assume derivations involving remnant movement. The present account could benefit from the adoption of van Riemsdijk's $f_{s e q}$, claiming that the remnant P-locP movement I propose for directionals targets Spec,Goal.

${ }^{12}$ See, e.g., Jackendoff (1983, ch.10) for such a proposal, and Haspelmath $(1997$, ch.1) for literature overview.

${ }^{13}$ See, e.g., Levinson (2003) for how the front axis is anchored in the object, and Zwarts and Winter (2000) for a formal implementation of 'located along an axis'.
} 
through (what is conceptualized as) the 'front' of the period denoted by ice age. This will lead to the right semantics just in case the front part of an interval is its beginning. The explanation for this usually relies on a cognitive model of time; I do not go into this here in detail; see, e.g., Jackendoff (1983, ch.10) and Haspelmath (1997, §4.2).

A use of vor which is interestingly different from (14) is in (15). Here again we see vor in a temporal use, but at first blush, the meaning is not compositional; vor einem Monat does not mean: an event $\mathrm{X}$ is located along an axis projected through the beginning of a(n arbitrary) month(-long interval). What (15) means is 'a month before the utterance time'. There are at least two possible analyses of (15) that maintain the idea that the meaning of spatial and temporal vor are identical, or at least related.

$$
\begin{aligned}
& \text { vor ein-em Monat } \\
& \text { before } a \text {-DAT month } \\
& \text { 'a month ago' }
\end{aligned}
$$

Haspelmath (1997) proposes that in order to obtain the correct meaning of (15), we have to do two things. First, we have to make sure that einem Monat 'a month' denotes 'the last month', i.e., the month-long interval preceding the utterance time. Then vor einem Monat will locate the Figure on the time axis as preceding the last month. But as Haspelmath observes, this is not enough, because while vor der Eiszeit in (14b) can mean 'ANYTIME, as long as that time precedes the ice age', vor einem Monat rather means 'EXACTLY before the last month'. Hence, we have to add that vor in (15) is semantically enriched by a component of pragmatic strengthening. I state the two ingredients as (16):

$$
\begin{aligned}
& \text { a. einem Monat 'a month' denotes 'the last month' } \\
& \text { b. vor in (15) is semantically enriched by a component of pragmatic } \\
& \text { strengthening }
\end{aligned}
$$

Such a solution has at least two problems. The first is that while vor now means roughly what we would expect (modulo the strengthening), the phrase einem Monat 'a month' does not. Rather than solving the puzzle, we shift it from the preposition to the noun phrase.

The second point of criticism concerns the way the proposal distributes the work load between the preposition and the noun phrase. Empirically, (16a) and (16b) are related. That is because we cannot allow 'a month' to denote 'the last month' across the board, but rather just in case it is the complement of vor. At the same time, vor obligatorily undergoes pragmatic strengthening just in case it is followed by a complement that undergoes the relevant semantic shift. However, the factual relatedness of these processes is theoretically obscured by the fact that (16a) targets the noun phrase, and (16b) targets the preposition. As things stand, we are left without a deeper understanding of why these processes should work in tandem, except for saying that they do.

I do not think that one can improve much on the analysis with the assumptions Haspelmath starts from. Specifically, he assumes that einem Monat is a 
semantic complement of the preposition, i.e., the Ground. This assumption in turn stems from the fact that the phrase 'a month' follows vor and bears dative. The step from ' $\mathrm{X}$ is a syntactic complement of a preposition' to ' $\mathrm{X}$ is a semantic complement of the preposition' is, however, not necessary, if there is a distinction, as here, between a structural object (DP in Spec,Asp-loc) and a semantic object (the Ground, complement of P-loc).

Hence, I propose instead that the phrase einem Monat is generated as a measure phrase, as suggested by the paraphrase of vor einem Monat: 'a month before utterance time'. ${ }^{14}$ The analysis is depicted below in (17): the semantic complement of vor is a silent deictic element UT, the utterance time. Vor 'before' projects an axis through the 'front' part of UT, i.e., in the direction towards past. The measure phrase 'a month' indicates the distance from UT to the Figure on this axis (see Zwarts and Winter 2000 for the precise semantics of measure phrases assumed here). This analysis gives us compositionally the meaning of (15) without the need to say anything special about the semantics of the expressions involved; 'before' means 'before', 'a month' means 'a month', and there is no pragmatic strengthening.

$$
[\text { a month }[\text { before }=\operatorname{vor}[\mathrm{UT}]]]
$$

The proposal gains support from two more facts. First, phrases similar to einem Monat surface as measure phrases in a variety of languages (see also van Riemsdijk 2007). I illustrate this on Persian: ${ }^{15}$
a. piš æz jæng
front from war
'before the war'
b. do sa'æt piš æz æmæl
two hours front from operation
'two hours before the operation'
c. do sa'at piš
two hours front
'two hours ago'
(Persian, Haspelmath 1997)
(Persian, Google)

(18a) shows that the preposition piš means 'before', and the Ground is marked by $\propto 2 z$. In (18b), we add a measure phrase to (18a). In (18c), the measure phrase still precedes the adposition, and it is formally identical to it. This in turn makes the measure phrase analysis of do sa'aet 'two hours' in (18c), the analogue of einem Monat, quite straightforward for Persian.

Second, even within German, one finds parallels between measure phrases and the object of vor in the meaning 'ago'. Recall here from (12b) that measure

\footnotetext{
${ }^{14}$ This analysis is inspired by van Riemsdijk's (2007) analysis of English a month ago.

${ }^{15}$ Piš also means spatial 'front', similarly to the German vor. The use of piš in spatial contexts, however, is restricted to particle-like uses. I thank Marina Pantcheva for her help with the Persian data. She notes that there is variation among speakers concerning (18), which I ignore here.
} 
phrases productively combine with modifiers such as halb 'half'. Now note that halb 'half' is fine in (19a), but not in (19b):
a. vor einem halben Monat
before a half month
'half a month ago'
b. *vor einem halben Konzert
beforea half concert

The semantically neat and independently confirmed analysis in (17) leads to an obvious question: why is it that if einem Monat is a semantic measure phrase, it does not share syntax with other measure phrases? Consider (20): here the measure phrase precedes the adposition, and it is marked accusative.

$$
\begin{aligned}
& \text { einen Monat vor dem Konzert } \\
& \text { a.ACC month before the.DAT concert } \\
& \text { 'a month before the concert' }
\end{aligned}
$$

To answer this question, a syntactic analysis must find (i) a way to force the assignment of dative to the measure phrase, rather than the usual accusative, and (ii) a way to make the measure phrase follow the adposition. (i) and (ii) are obviously related: to bear dative and to follow the adposition are the two properties that objects of adpositions have in German. The analysis must then explain how a measure phrase can become an object of the preposition. ${ }^{16}$

I think that a satisfactory answer can be provided only by a theory which has a viable notion of 'structural object of an adposition'. A theory which employs default case does not, and hence cannot allow the measure phrase to turn into one. Such a theory then needs a special mechanism to account for the loss of accusative on the measure phrase (just in case the Ground is null), such that the measure phrase's retreat to the default would be required.

Further, the position of the measure phrase has to be taken care of by another mechanism. One can adapt the proposal of Svenonius (2010b) and say that just in case the Ground is null, the adposition moves across the measure phrase. However, such a movement would then be expected to take place also in Persian, leading to the expectation that even if the measure phrase is not marked as the object of the adposition, the Ground's absence will force the movement of the adposition regardless. However, I know of no such language. If the measure phrase looks like a measure phrase, the adposition won't cross it. ${ }^{17}$

\footnotetext{
${ }^{16}$ Postal (1974) extensively defends a similar point for (English) ECM: the subject of the embedded infinitive becomes the object of the matrix verb not only for case, but also word order and other properties.

${ }^{17}$ I base my judgment on the sample of cca. 50 languages collected in Haspelmath (1997). Similar implication goes the other way round: if the measure phrase has the same marking as the Ground, then it follows the adposition in prepositional languages (Latin, Serbo-Croatian, Lithuanian, Latvian, Modern Greek, Albanian), and precedes it in postpositional languages (Hungarian, Tamil).
} 
The problem of ordering also arises for the approach which relies on covert case checking. On that approach, it is understandable that a measure phrase can covertly check dative instead of the Ground (i.e., when the Ground is null). However, no reordering is expected.

In the present theory, only one extra assumption is needed to accommodate the analysis of vor einem Monat: that Spec,Asp-loc must be filled by overt material in German. I show the derivation in (21), starting from the structure in (17). First, we add Asp-loc. The Ground of vor is phonologically null, and hence unable to satisfy the need of Spec,Asp-loc for an overt phrase. The only available alternative is to move the measure phrase, see (21a). As a result, the measure phrase is marked dative. This is followed by a remnant movement of the P-locP to Spec,XP in (21b). Pronounced elements are in bold. ${ }^{18,19}$

$$
\begin{aligned}
& \text { a. }[1 \text { month-dat Asp-loc }[1 \text { month }[\text { before }[\mathrm{UT}]]]] \\
& \text { b. }\left[{ }_{X P}\left[{ }_{P-\operatorname{loc} P} \text { before UT }\right]_{j}\left[\mathbf{1} \text { month-dat }{ }_{i} \text { Asp-loc }\left[\mathrm{t}_{i} \mathrm{t}_{j}\right]\right]\right]
\end{aligned}
$$

To sum up: the derivation of locative PPs with overt checking of dative and P-locP movement is independently needed to account for cases where a semantic measure phrase becomes the structural object of a preposition. This leads to the conclusion that dative in PPs is not a default case. To the extent that directional PPs are based on locative PPs (including the dative assigner), this also means that the Ground argument passes through two case positions.

\subsection{A broader context}

Before leaving the topic of locatives, I would like to put my proposal in a broader context. The structure of locative PPs now involves an overt movement of a DP to Spec,Asp-loc, and a remnant movement of P-locP higher up. Such derivations find direct parallels in some of the recent contributions to the debate on word order in the verb phrase. For instance, Taraldsen (2000) and Hróarsdóttir (2000) propose that VO order (in some languages) is derived by

\footnotetext{
${ }^{18}$ It is possible that the movement in $(21 \mathrm{~b})$ moves a larger constituent which includes the trace of the measure phrase. That would mean that the measure phrase will always precede the locative $\mathrm{P}$ unless it moves out of that constituent, as in (21a). However, it is also possible that the positioning of the measure phrase is independent of the P-locP movement. I leave this question for future investigations.

${ }^{19}$ The same account can be given to English (ia), discussed in Kayne (2004) and Svenonius (2010b). What the authors note is that (ia) does not mean 'get behind that place there', but rather something like (ib).
}

$$
\begin{aligned}
& \text { a. Get behind there! } \\
& \text { b. Get there behind something! }
\end{aligned}
$$

(Svenonius 2010b:ex.21a)

The pair of English examples is similar to the German vor: just in case the Ground argument of $\mathrm{P}$ is silent, an expression that would normally precede the adposition (there), comes to follow it. Hence, I take there to move to Spec,Asp-loc — the resulting situation may be comparable to expletive there in Spec, TP-and let the P-locP with a silent Ground move to the left of it. 
first moving the object to the left of the verb, and then by moving the remnant VP back to the left of the object (similarly to the derivations in Kayne 1998).

One also finds parallels to the present proposal within the literature on the structure of PPs. Noonan (2007) discusses PPs in colloquial German which involve doubling of a locative adposition. She proposes that this doubling is the result of multiple spell out of a single adposition. ${ }^{20}$ Due to the fact that the copies are separated by both head and phrasal material, she concludes that the copies are related by phrasal movement of the PP. Noonan's PP movement is similar to the one I propose here, and to the extent that her analysis is right, the doubling of P-loc in German provides independent support.

A proposal which argues for the existence of DP movement inside PPs with dative is Bošković (2004b). He bases his argument on the existence of Q-float in PPs such as the German example below: ${ }^{21}$

Ich habe mit den Studenten allen gesprochen.

I have with the students all spoken

'I spoke with all the students.' (German, Bošković 2004b:ex.7)

Bošković assumes the analysis of Q-float by Sportiche (1988), which derives Q-float by stranding. He further points out that quantifiers cannot be stranded in the base-position; hence, before quantifier floating takes place, the phrase 'all the students' has to undergo a prior movement. If correct, the reasoning points to the existence of a movement (independent of Q-float) to the left of mit 'with', and perhaps in PPs with dative DPs quite generally. ${ }^{22}$

These two proposals support the view presented here. (I) the availability of Q-float suggests movement of the DP to the left of P-loc, a case position; (II) the copying construction reveals the existence of a movement of the adposition.

\section{The case-movement correlation}

I now proceed to provide supporting evidence for the derivations leading to directional interpretation. I show that for alternating adpositions, the German accusative corresponds to postpositional order in Dutch. Within the same class of adpositions, dative in German corresponds to prepositional order in Dutch. The idea here is that this parallel between movement and case exists

\footnotetext{
${ }^{20}$ This is similar to van Riemsdijk (1990), but see also van Riemsdijk and Huybregts (2002) and van Riemsdijk (2007) for an alternative view.

${ }^{21}$ All the examples I was able to find in the literature for both German and Dutch use the adposition 'with'. Henk van Riemsdijk (p.c.) informs me that for him, examples such as (21) are quite marginal, and the judgment is the same for spatial PPs with a floated quantifier.

${ }^{22}$ There is a related discussion in Koopman (2000) surrounding her example 12. See also den Dikken (2010, ftn. 8) for an opposing view.
} 
because Dutch lacks the XP remnant movement proposed for German. As a consequence, Dutch shows on its sleeve the DP movement to Spec,PathP that I have proposed for the German accusative, and it also shows the lack of movement to Spec,Path which leads to the emergence of the dative.

The Case-Movement correlation of German and Dutch

a. $\quad \mathrm{DP}>\mathrm{P}($ Dutch $)=\mathrm{ACC}($ German $)$

b. $\mathrm{P}>\mathrm{DP}($ Dutch $)=\operatorname{DAT}($ German $)$

As with the locative-directional alternation, a closer look reveals that the data are messier than one would like. However, I argue that the non-isomorphisms of German case and Dutch order do not blur the relevance of the parallel. I show that the two equations in (23), which I call the Case-Movement correlation (CMC), capture quite well the commonalities and differences of the two languages. CMC is then something any theory should like to capture. ${ }^{23}$

\subsection{The locative-directional alternation in Dutch}

As now expected, Dutch has a locative-directional alternation which is similar to the one observed for German. The difference is that what German 'expresses' by case, Dutch handles by word order (24). The relevant observation is that prepositional order with Dutch alternating adpositions (in 'in' and op 'on') corresponds to the assignment of dative in German alternating adpositions, in the sense that they both lead to a locative interpretation of the alternating adposition. ${ }^{24}$ Complementarily, the assignment of accusative with alternating adpositions corresponds to the postpositional order in the same instances, both leading to the directional interpretation.

a. Willemijn zwom in het meer.

Willemijn swam in the lake

'Willemijn swam in the lake.' locative / *directional

b. Willemijn zwom het meer in.

Willemijn swam the lake in

'Willemijn swam into the lake.' *locative / directional

(both Dutch, Gehrke 2008:90, 91)

A further parallel between German case and Dutch word order is that the postpositional order (24b) is available only under the directional interpretation,

\footnotetext{
${ }^{23} \mathrm{CMC}$ has been observed before, but it has never been defended as a central point (as far as I know). I discuss the literature towards the end of the section.

${ }^{24}$ There are some contexts in Dutch where prepositional phrases can be part of a goal of motion construction. I comment on this in the next subsection.
} 
and never under the locative interpretation (see the discussion in den Dikken 2010). ${ }^{25}$ In German, the accusative is also available only under the directional interpretation. I put the generalization below:

Accusative and postpositional order have the same semantic correlate

a. Dutch: $\mathrm{DP}>\mathrm{P} \rightarrow$ directional $\mathrm{PP}$

b. German: $\mathrm{ACC} \rightarrow$ directional PP

Recall that to account for (25b), I have followed den Dikken by proposing that accusative is assigned to the Spec of a head available only in directionals. Departing from den Dikken, I have proposed that case is checked under overt movement to that position. The same DP movement can now be held responsible for (25a). This has in fact been independently proposed for Dutch (24b) in Koopman (2000), Helmantel (2002), and den Dikken (2003, 2010).

The differences between German and Dutch alternating PPs are then two. One, as highlighted in Section 4, German masks the movement of a DP to Spec,PathP by an additional step of remnant movement. This movement is absent in Dutch. Two, Dutch does not have morphological case, and hence, does not (overtly) show the distinction between dative and accusative, manifested in German.

This is not to say that the same adpositions which show case alternation in German show alternation in Dutch: only a subset of German alternating adpositions alternates for order in Dutch. For instance, the adposition voor 'before' can only surface as a preposition (26). I call this the Productivity problem: any theory must have a way to lexically distinguish alternating and non-alternating adpositions. ${ }^{26}$

Hij rijdt $\{*$ de deur $\}$ voor $\{$ de deur\}.

he drives the door before the door

'He drives to a place in front of the door.'

(Dutch, den Dikken 2010, exs. 1,2)

Such differences, however, are attested between other languages as well, and they are orthogonal to the fact that Dutch expresses the alternation by wordorder, and German by case. For instance, Czech and Russian express the alternation, among others, by changing instrumental to accusative with a set of

\footnotetext{
${ }^{25}$ I have to mention here that I ignore a feature of both German and Dutch, the so called $r$ pronouns. These are elements like 'here' and 'there', which exhibit a rather peculiar behavior (similar to English there in He spoke thereof). There does not seem to be a consensus on their proper analysis; van Riemsdijk (1978), Koopman (2000) and den Dikken (2003) treat them as complements of adpositions which undergo leftward movement, Abels (2003) and Noonan (2007) argue that they are base-generated higher up.

${ }^{26}$ See Zwarts (2008) for relevant discussion.
} 
cognate adpositions (e.g., Cz./Rus. za 'behind'). However, Czech před 'before' alternates (like the German one), but Russian pered 'before' does not (like the Dutch one). I treat this complication later on; for the time being, I note that for items which do alternate, the parallel is complete.

A further demonstration of both the validity and the limitations of CMC can be shown for the Route adposition 'through', rendered by German durch and Dutch door. The (strictly directional) preposition durch 'through' assigns accusative in German (27a), and its Dutch counterpart door has the possibility to act as a postposition (27b). ${ }^{27}$
a. durch das $/ *$ dem Haus
through the.ACC the.DAT house
'through the house'
b. Hij liep \{het bos\} door \{het bos\}.
he ran the wood through the wood
'He walked (all the way) through the forest.'

(Dutch, Gehrke 2008, ex. 104)

As can also be observed, the parallel is less than perfect, however, because door can also be a preposition, but durch only takes accusative. What does the non-isomorphism of door and durch mean from the perspective of CMC? It surely renders it incorrect as a statement about the identity of Dutch word order and German case at the level of every single adposition. But that we know already from the difference between German vor and Dutch voor.

However, (27) does not make CMC incorrect in the sense that both accusative and postpositional order are available only in directional PPs. From that perspective, German and Dutch 'through' pattern as expected: with the properties they have in the relevant examples (postposition/accusative assigner), they must be directional (in those constructions), which they are. The challenge is then to find suitable lexical entries for durch and door such that door will allow for more possible derivations compared to $d u r c h .^{28}$

\subsection{The other side of the coin}

I now proceed to look at the other part of the generalization, the correspondence of dative and prepositional order. In German, dative can lead either to locative (with alternating adpositions) or directional interpretation (as with $z u$ 'to'). The same holds for prepositional order in Dutch. With alternating

\footnotetext{
${ }^{27}$ I am grateful to Berit Gehrke for pointing out the relevance of the pattern in her review and for providing me with detailed information concerning the behavior of durch 'through' in German. Unfortunatelly, I cannot present a detailed discussion here for reasons of space. See Gehrke (2008, $85,86)$ on Dutch door, in particular on the data in $(27 \mathrm{~b})$.

${ }^{28}$ As pointed out by two reviewers, similar issues as with Dutch door 'through' arise with af 'off' and uit 'out.' See Caha (2007a) for the discussion of af from the present perspective.
} 
adpositions, prepositionality leads to locative interpretation (24a), ${ }^{29}$ and in (28) I give a directional prepositional PP. (29) summarizes the pattern:

Marjo is naar het meer gezwommen.

Marjo is to the lake swum

'Marjo swam to the lake.' *locative / directional

(Dutch, Gehrke 2008:107)

(29) Dative and prepositional order have the same semantic correlate

a. Dutch: $\mathrm{P}>\mathrm{DP} \rightarrow$ locative or directional

b. German: DAT $\rightarrow$ locative or directional

We see that empirically, the two distinct properties (dative in German, prepositionality in Dutch) are connected by their (lack of) effects on interpretation. Theoretically, the properties are unified by the lack of movement to Spec,Path. The movement is unavailable for locatives, and also for some directionals.

Apart from the commonality (29), there are independent differences. For instance, locative PPs in German and Dutch interact with their environment differently, see Gehrke $(2007,2008)$ and den Dikken (2010). In Dutch, prepositional PPs (including PPs with alternating adpositions) can denote the goal of motion in the right context; compare (30a) with (24a). German alternating Ps with dative do not have this option, see (30b). ${ }^{30}$
a. Rick sprong in het meer.
Rick jumped in the lake
'Rick jumped in the lake.' locative / directional
b. Silke sprang im See.
Silke jumped in.DAT lake
'Silke jumped in the lake.' locative / *directional

(Dutch)

(both exs. from Gehrke 2008:90, 96)

I follow Gehrke and den Dikken in claiming that the Dutch prepositional directionals under discussion are 'internally' locative, and their directional interpretation is caused by the surrounding material. ${ }^{31}$

\footnotetext{
${ }^{29}$ Immediately below the example, I will show that this statement needs to be qualified, but not abandoned.

${ }^{30}$ Note that naar (28) contrasts with prepositional in (24a), and patterns with postpositional in (24b). Both naar and postpositional in are directional regardless of context.

${ }^{31}$ See also Ramchand (2008) and Tungseth (2008) for comparable data and conclusions. See den Dikken (2010) and Gehrke (2008) on investigation of the particular environments that are relevant in Dutch. Apart from certain verbs, these include the PP-with-DP construction, and nominal idioms (see den Dikken 2003:ftn.10). I am grateful to two anonymous reviewers for pointing these out to me.

In this context, consider also the observation by another anonymous reviewer who points out that with some Dutch verbs (mostly various verbs of putting and body positioning), the prepositional version becomes the only option available (ia). German persists with a directional (ib).
} 
The difference between German and Dutch in (30) is not caused by the fact that Dutch expresses the alternation by word order, and German by case. Ancient Greek (Luraghi 2003) is like German in that it shows alternation in case, but like Dutch in that certain environments allow for a directional reading of the PP with dative. ${ }^{32}$

kat' ár' hézet' ep' eskhárēi en koníeisi pàr purí
down PTC sat on fireplace.DAT on ash.DAT by fire.DAT
'He sat down on the hearth in the ashes by the fire.'

(Ancient Greek, Luraghi 2003:133)

\subsection{Case Preservation and Order Preservation}

Recall now the explanation of why $z u$ 'to' governs dative: $z u$, meaning 'TO AT', lexicalizes (among others) the Path head, the Spec of which is targeted by movement of the DP in alternating adpositions. I have proposed that this movement is unavailable for $z u$ 'to', due to the activity of Doubly Filled Nothing: a head which is lexicalized cannot have an overt Spec.

Now if it turns out that Dutch lacks movement to the left of an adposition in comparable PPs where German lacks accusative, then we have a clear confirmation of our hypothesis. This is borne out. Recall that German directional adpositions that require the dative are strictly directional, see (7). For Dutch, we have seen in (28) that naar 'to' is a directional preposition-and it is strictly directional. Other directional prepositions are tot 'to, up to', van 'from', and both of them strictly directional as well. Apart from these, there are a few adpositions which are directional and occur both as prepositions and

(i) a. $\quad$ in $\}$ het gras $\{*$ in $\}$ gaan zitten

in the grass in go sit

'sit down in the grass'

b. sich ins Gras setzen

(Dutch, data due to an anonymous reviewer)

self in.ACC grass sit

'sit down in the grass'

(data due to an anonymous reviewer)

This reminds me of a similar contrast between English and Finnish investigated in Fong (1997). In Finnish, one forgets something INTO the train station, while Indo-European languages I know prefer simple locative IN.

Henk van Riemsdijk (p.c.) further points out that the postpositional construction is unavailable for figurative readings. (iia) can have both literal and figurative interpretation, while (iib) only literal:

(ii) a. De muis is in de val gelopen.

the mouse is in the trap ran

'The mouse went into the trap.' (ambiguous)

b. De muis is de val in gelopen.

the mouse went the trap in ran

'The mouse went into the trap.' (literal only)

(Dutch, H. van Riemsdijk, p.c.)

${ }^{32}$ As in footnote 31 , I again use the verb 'sit' to obtain a pair close to minimal. 
postpositions: door 'through', uit 'out of', and af 'off', although the last one is very rarely a preposition ( $\mathrm{I}$ am drawing here on the appendix of Helmantel 2002). Since these items have a prepositional and directional incarnation (and the directional reading does not depend on the environment here), they are all relevant to the generalization. As predicted, all of them are strictly directional. ${ }^{33}$

And so, along with the Case Preservation Generalization (32), we can put forth the Order Preservation Generalization (33). Case Preservation and Order Preservation are both sensitive to the same property: strict directionality. This is neatly captured by the current proposal: in Dutch, like in German, movement to Spec,PathP is blocked when Path is lexicalized by a strictly directional adposition. The observations are summed up in (34).

The Case Preservation Generalization (German): If a directional adposition assigns dative, it is strictly directional.

The Order Preservation Generalization (Dutch): If an adposition precedes its complement DP in a directional PP, the adposition is strictly directional.

Dative Case and prepositionality are connected to the same (abstract) class of adpositions.

a. German: DAT \& DIR $\rightarrow$ strict directionality

b. Dutch: P > DP \& DIR $\rightarrow$ strict directionality

The final point I would like to make concerns an alternative view which has been unaddressed so far: what if the difference between German and Dutch is not the presence/absence of remnant movement, but covert nature of the DP movement to Spec,Path in German? There is one strong reason why the movement is best thought of as overt: it is the only way to capture the parallel between German and Dutch. If Dutch word order and German case were one the result of overt, and the other of covert movement, there is no guarantee that the two distinct processes would deliver the same result. This is especially relevant in this context: it is quite plausible that covert movement does not care about the phonological realization of Path, while overt movement does.

\section{4 $\mathrm{CMC}$ in previous accounts}

My formulation of CMC has at least two predecessors. I will briefly review them here, and say why I think that the present account is different, and perhaps better.

In den Dikken's system, word order in Dutch simple postpositional phrases is the result of overt movement of the Ground DP to Spec,Asp-dir, the same position which is responsible for accusative in German. This movement is enabled by overt incorporation of P-loc into the silent $\mathrm{P}$-dir, since it is only

\footnotetext{
${ }^{33}$ Note that I still ignore context dependent directionals.
} 
after this incorporation that the complement of P-loc becomes the derived complement of P-dir (by Baker's 1988 Government Transparency Corollary), eligible for such movement. Further, given that P-loc can incorporate into Pdir only if there are no intervening projections, we must conclude that only structures which lack Asp-loc will lead to (simple) postpositional order. Now recall that this is exactly the same type of structure which led to the assignment of accusative in German, because the presence of Asp-loc would cause the emergence of dative. Despite the structural alliance of postpositional order and accusative, each of them is in the end derived by distinct processes, governed by different principles. The German situation is handled by covert movement and the Uniqueness of Case Assignment, while the account of Dutch relies on overt movement and the Government Transparency Corollary.

The situation is similar in Gehrke (2008). She proposes that "postpositions in Dutch are the result of complex predicate formation [...], which takes place under the same conditions under which accusative case in German emerges" (p.141). However, the actual processes are quite different. While "accusative case inside PPs marks the subject-predicate relationship when a secondary predicate is turned into a part of the verbal predicate" (p.136), the postpositional order is the result of a (rightward) movement of the adposition.

Both of these accounts, like the present one, draw a substantial parallel between Dutch word order and German case. However, they both rely on the interaction of identical 'deep' structures with different principles, which conspire to deliver CMC indirectly. The present account takes CMC at face value: accusative in German is the result of the same process which moves the noun to the left of the adposition in Dutch. ${ }^{34}$

\subsection{Conclusions and prospects}

This section closes the first part of the paper. I have argued that both dative and accusative in German PPs are checked under overt movement of the DP to the Spec of a designated position. Further, the dative is checked first, and it shifts to accusative under a subsequent movement. I will now proceed to develop a theory of how this case shifting happens. I also start paying attention to the implications of the present model: what happens to datives assigned by verbs? Can they also be 'overridden'?

\section{The problem of the oblique and the productivity problem}

Consider the view, recently elaborated in Woolford (2006), that oblique cases are assigned to DPs in the base position, either to reflect the $\theta$-role or to satisfy

\footnotetext{
${ }^{34}$ As highlighted in Section 5, this probably also applies to the system developed in van Riemsdijk (2007). However, van Riemsdijk himself does not discuss possible extensions of his system for Dutch.
} 
lexical requirements of a particular assigner. Still on this view, oblique case cannot change depending on the environment the base position is embedded into, or depending on any potential A-movement processes the oblique is subject to; this being due to the Uniqueness of Case Assignment. ${ }^{35}$

One of the core contrasts that the theory aims to capture is given in (35) and (36). As the contrast shows, dative (in German) cannot change to nominative under passivization (35), while accusative can (36). This follows if dative is assigned in situ, and cemented for any mutations by Case Uniqueness. I call passives of this type 'be-passives' henceforth, because the copula is 'be'.

Dative preservation under passivization

a. Oswald hat dem Präsidenten gehuldigt. Oswald has the.DAT president given-homage

b. Dem Präsidenten $/ *$ der Präsident wurde gehuldigt. the.DAT president the.NOM president was given-homage

Promotion of the accusative under passivization

a. Oswald hat den Präsidenten ermordet. Oswald has the.ACC president assassinated

b. Der Präsident wurde ermordet. the.NOM president was assassinated

(Bayer et al. 2001, exs. 5a-6b)

If this account of (35) is correct, adpositions that assign either an oblique or accusative case (depending on a larger structural context) are predicted not to exist. But given that they do, we have to adopt the view that dative is also sensitive to a larger structural context. Such a theory, however, has to account for the resistance of the dative to disappearing in (35b). I call this the Problem of the oblique: why is it that dative can sometimes change to a structural case, and sometimes it cannot?

One option would be to explore the possibility that the dative in PPs is different from the dative in VPs. However, this is not the path I would like to take, partly due to the similarity of the Problem of the oblique to the Productivity problem encountered with Dutch voor 'before' (26). I illustrate the same issue on German bei 'at' below:

a. Wir sind bei ihm. we are at him.DAT

'We are at his place.'

b. *Wir gehen bei ihn. we go at him.ACC

'We are going to his place.'

\footnotetext{
${ }^{35}$ Other theories use different tools, but almost everybody seems to agree that oblique cases cannot be promoted to structural cases. See, e.g., Marantz (1991) and McFadden (2004:\$4.6) for Distributed Morphology proposals yielding these consequences. See, however, Svenonius (2010a) for an interesting proposal for Icelandic dative-nominative alternations.
} 
As highlighted above, any theory has to encode the fact that not all adpositions allow their oblique complement to turn into a structural case. In the ideal case, the same mechanism will account for the fact that dative cannot shift to a structural case in be-passives. What could this mechanism be?

As far as I can tell, there is only one solution to the Productivity problem: the locative and the directional version of an adposition must be distinguished by at least one feature F. If the feature matrices were the same, the Productivity problem would have no solution for the simple reason that there would be no way to (lexically) distinguish alternating from non-alternating adpositions. An alternating adposition is then an instance of syncretism: two distinct feature structures have the same exponent.

This conclusion is supported by data from Ancient Greek (Smyth 1974; Luraghi 2003:72). Recall from Table 1 that Ancient Greek has the adposition para 'at' which alternates between dative (for location) and accusative (for direction). With the locative concept 'IN', the locative version again takes dative, and the directional version again takes accusative. However, the forms of the adpositions differ: we get en 'in' with dative, and eis 'into' with accusative. This overt distinction independently confirms that the locative-directional alternation not only changes the dative (and other obliques in other languages) to accusative, but also changes the feature composition of the adposition.

$$
\begin{aligned}
& \text { a. } \\
& \text { b. } \\
& \text { parà }+\mathrm{DAT}=\mathrm{ACC}=\text { to } \mathrm{X}
\end{aligned}
$$

c. $\quad$ en $+\mathrm{DAT}=$ in $\mathrm{X}$

d. eis $+\mathrm{ACC}=$ into $\mathrm{X}$

I propose to connect the two facts (change of case and change of the adposition) in the following way. First, dative (KP) structurally contains accusative (AccP). When the DP shifts from dative to accusative, it does so by stranding the layer of the oblique case K (39). Advantageously, the stranded K can also be seen as the feature that distinguishes the directional from the locative adposition: eis 'into' $=$ 'in' $+\mathrm{K} .{ }^{36}$ Consequently, the idea about the distinction between alternating and non-alternating adpositions is that only alternating adpositions are able to spell out the additional feature K.

$$
\text { [ accusativeP ] Path ... [dative P K [ accusativeP ] ] Asp-loc ... }
$$

This idea then extends to dative passives: they are possible in principle, but some element must spell out the stranded shell. I will follow some of the literature and argue that such elements in German are the (semi-)auxiliaries bekommen and kriegen, both 'get'. I refer to such passives as 'get-passives'.

\footnotetext{
${ }^{36} \mathrm{Granted}$ this equation, it becomes tempting to analyze English into as [in $+\mathrm{K}(=$ to $\left.)\right]$. The analysis would claim that the DP in English alternates between dative and accusative in the manner discussed for German, and when the DP strands the dative $\mathrm{K}$ to become accusative, $\mathrm{K}$ is spelled out by an independent marker 'to'. However, the status of dative on DPs in English is not clear (to me).
} 
German bekommen/kriegen passive

a. Der Chirurg entfernte dem Patienten die Milz. the.NOM surgeon removed the.DAT patient the.ACC spleen

b. Der Patient bekam/kriegte die Milz entfernt. the.NOM patient got / got the.ACC spleen removed

(Bayer et al. 2001, ftn.1)

The proposal described above is the core of the so-called Peeling Theory of Case proposed by Starke (2005), which I introduce systematically in the next section, defending the empirical points as we go.

\section{Peeling}

The Peeling Theory of Case has been proposed in classes taught by M. Starke. Written sources include: Medová and Taraldsen (2007), Caha (2007a, 2009), Taraldsen and Medová (2007), Medová (2008). The Peeling Theory of Case builds on two ingredients which I am going to introduce in turn. The first one is the idea that individual cases are composed of features which are organized in a hierarchy, the functional sequence (see Caha 2009). The second idea is that when DPs move, they strand some of these features, which leads to a change of one case into another under movement.

\subsection{Case decomposition}

I start by defending the decomposition of case relevant for the present account; namely that accusative is contained inside the dative, an idea extensively discussed in Bayer et al. (2001):

(41) Bayer et al. (2001): Decomposition of case

a. Structural cases: [ DP ]

b. Oblique cases: [ K [ DP ] ]

Under one possible interpretation of (41), the dative is built on top of the accusative by the addition of a feature (K). In (42), I depict such an interpretation. I also dissociate accusative (F) from the $\mathrm{D}$ projection, dedicated to determiners, because the exponent of accusative and the determiner are usually two distinct morphemes, each plausibly heading its own projection: ${ }^{37}$

$$
\begin{aligned}
& \text { a. Accusative: [F [DP ] ] } \\
& \text { b. Dative: [K [F [DP ] }
\end{aligned}
$$

There are several reasons for adopting (42) as a universal sequence, and I briefly mention two of them. The first piece of evidence comes from the

\footnotetext{
${ }^{37}$ Bayer et al. (2001) opt for a different interpretation. They say that case is a property of NP, and that if an NP has an oblique case, this requires KP to be present higher up.
} 
morphology of some languages, where the dative is morphologically based on the accusative. This pattern usually arises when the accusative is formally unmarked, and the dative bears a suffix; the case of German Brüder-Brüder$n$ 'brothers, nom./acc. - dat.' However, I know of only one language where the pattern comes out the other way round: Icelandic. The overwhelming dominance of the former pattern supports the idea that dative has more structure than accusative, the proof being the extra piece of the dative morphology. ${ }^{38}$

Another piece of evidence for a cross-linguistic validity of such a structure comes from the cross-linguistic distribution of case. Blake (1994) observes that if a language has a dative, it also has an accusative. 'Not to have a dative' means that dative is expressed either by a preposition (e.g., as in the Bulgarian na profesor- $a$, lit. 'onto professor-DEF.ACC'), or by a postposition.

I won't consider the division between postpositions and case suffixes here, and focus on the (sharper) division between prepositions and suffixes. ${ }^{39}$ The crucial observation is that there is no language with dative marked by a suffix, and accusative by a preposition. This follows from the proposed decomposition and the assumptions about movement in the extended NP recently advocated

\footnotetext{
${ }^{38}$ Two reviewers ask if there are languages with overt accusative, and dative formed by further suffixation. A nice illustration is West Tocharian (Krause and Werner 1960, Krause and Slocum 2010), an Indo-European language documented by texts from 6-8 century AD. Four example paradigms are below, GEN/DAT is a case which fuses the functions of the adnominal complement and the indirect object:
}

\begin{tabular}{|c|c|c|c|c|}
\hline & horse, SG & horse, PL & man, sG & man, PL \\
\hline NOM & yakwe & yakwi & enkkwe & en̉kwi \\
\hline $\mathrm{ACC}$ & yakwe & yakwem & ennkwem & en்kwem \\
\hline GEN/DAT & yakwents & yäkweṃts & enkwents & enkwwemts \\
\hline
\end{tabular}

We see that the GEN/DAT plural $(m-t s)$ is based on the ACC plural $(m)$. This does not hold for singular, where the GEN/DAT (-nts) attaches to the stem. In the case of the paradigm 'horse, sg.' this leads to a situation similar to the German Brüder - Brüder-n 'brothers, nom./acc.pl. - dat.pl.'

The relevance of the decomposition is strengthened by two facts. First, when an adjective modifies a noun in GEN/DAT, the adjective either agrees (ia), or shows ACC (ib). (ia) shows that the GEN/DAT is eligible for agreement. (ib)shows that the ACC (contained in the GEN/DAT) can also be targeted by agreement. This is not restricted to cases where the relation between GEN/DAT and ACC is morphologically transparent (ic).
a. krenta-mts sāmna-mts good-DAT.PL men-DAT.PL
b. kleśanmașṣe-m sana-ṃts Klesa-AcC.PL enemies-DAT.PL
c. anmalāske-m kässi-ntse commiserative-ACC.SG teacher-DAT.SG

(West Tocharian, Krause and Werner 1960:92)

Second, when two nouns in GEN/DAT are coordinated, then either both bear GEN/DAT, or only the last one, and the first one is in ACC. This can be understood as a FP coordination under a single K (see Krause and Werner 1960, 90 for examples). I do not know of a language where the patterns would come out the other way round.

${ }^{39}$ Note that I take these 'case-like' prepositions to be the lexicalization of case heads, and not of any of the heads associated with P-loc or Path. Consequently, the DP movement I talk about 
by Cinque (2005). Cinque proposes that a nominal constituent of a certain size-denoted as a DP in (43) - moves (as a phrase) to a particular height in its extended projection. Languages vary with regard to how high the movement can reach, and the size of the constituent that moves. Combined with our decomposition, the assumptions lead to the following conclusions.

If in a language the movement crosses $\mathrm{F}$, the language has an accusative suffix. This happens in both Bulgarian and German. In Bulgarian, this is as high as a noun can get. As a consequence, the morpheme na 'onto', which spells out K, precedes the whole extended NP, see (43a). In German, however, the noun can move above K. Consequently, German has a dative suffix (43b). ${ }^{40}$

The division of labor between prepositions and case suffixes
a. B:
$[\mathrm{K}=n a$
$[\mathrm{DP}=$ profesor -
$[\mathrm{F}=a$
b. $\quad \mathrm{G}: \quad[\mathrm{DP}=$ Brüder $-\quad[\mathrm{K}=-n$
$[\mathrm{F}=\varnothing \quad \mathrm{t}-\mathrm{DP}]]]$

It is impossible, however, for a language to express dative as a suffix without having an accusative suffix as well. That would mean that the DP moves higher than $\mathrm{K}$, while staying lower than F. That is impossible, and hence we derive the gap in the world's languages pointed out by Blake. An essential part of the deduction is the proposal that the dative structurally contains the accusative.

\subsection{Case by stranding}

The second part of the Peeling Theory is an assumption concerning the way DPs move from one position to another. The core is that once an extended NP lands in a position to which it has been attracted, it is frozen for further movements. I follow Rizzi (2004) and call this Criterial Freezing, and the attracting position the Criterial Position.

$$
\begin{array}{lllllll}
\text { a. } & * & {[\mathrm{Y}[\mathrm{X}[\mathrm{DP}]]]} & \ldots & {[\mathrm{Y}[\mathrm{X}[\mathrm{DP}]]] \mathrm{A}} & \ldots & \mathrm{t}-\mathrm{YP} \\
\text { b. } & \text { ok } & {[\mathrm{X}[\mathrm{DP}]]} & \ldots & {[\mathrm{Y}[\mathrm{X}[\mathrm{DP}]]] \mathrm{A}} & \ldots & \mathrm{t}-\mathrm{YP} \\
\text { c. } & \text { ok } & {[\mathrm{DP}]} & \ldots & {[\mathrm{Y}[\mathrm{X}[\mathrm{DP}]]] \mathrm{A}} & \ldots & \mathrm{t}-\mathrm{YP}
\end{array}
$$

In (44a), YP is attracted from the base position (t-YP) to satisfy a requirement of the attracting position A (the middle position of YP in (44a)). YP has reached the Criterial Position; any further movements of YP are blocked by Criterial Freezing, hence the unavailability of (44a). However, sub-extraction from YP is allowed: either XP (44b), or DP (44c) can move higher up.

Granted the two proposals, we now capture the shift from dative to accusative as a case of sub-extraction. The locative structure is in (45). The

\footnotetext{
below is a movement within the extended NP, and not a movement of the extended NP within the extended projection of another category (e.g., P-loc).

${ }^{40}$ The table is simplified for expository purposes; I here leave aside a whole number of issues: the clitic-like nature of the Bulgarian affix which targets the second position within the DP, and similar issues with German case morphemes. The complications change the details of the account, but not the logic: raising goes as high as $\mathrm{X}$, but not further.
} 
Ground DP has moved to the dative position Spec,Asp-loc, and it has been crossed over by the remnant P-locP movement. I do not think of the KP movement as 'checking' of the dative case in the traditional sense; $\mathrm{K}$ is not 'uninterpretable' and has no need to move. KP moves to satisfy the requirements of Asp-loc. P-locP is spelled out by the adposition in, and the dative KP by dem Zimmer 'the.DAT room'.

In (46), we add the Path head to the locative structure, a Spec of which attracts the accusative. The accusative then sub-extracts from within the dative, and lands in Spec,Path. The movement satisfies the requirement of Path, not of Acc. In German (but not in Dutch), this is followed by a remnant movement of the whole XP. The XP is spelled out by in. ${ }^{41}$

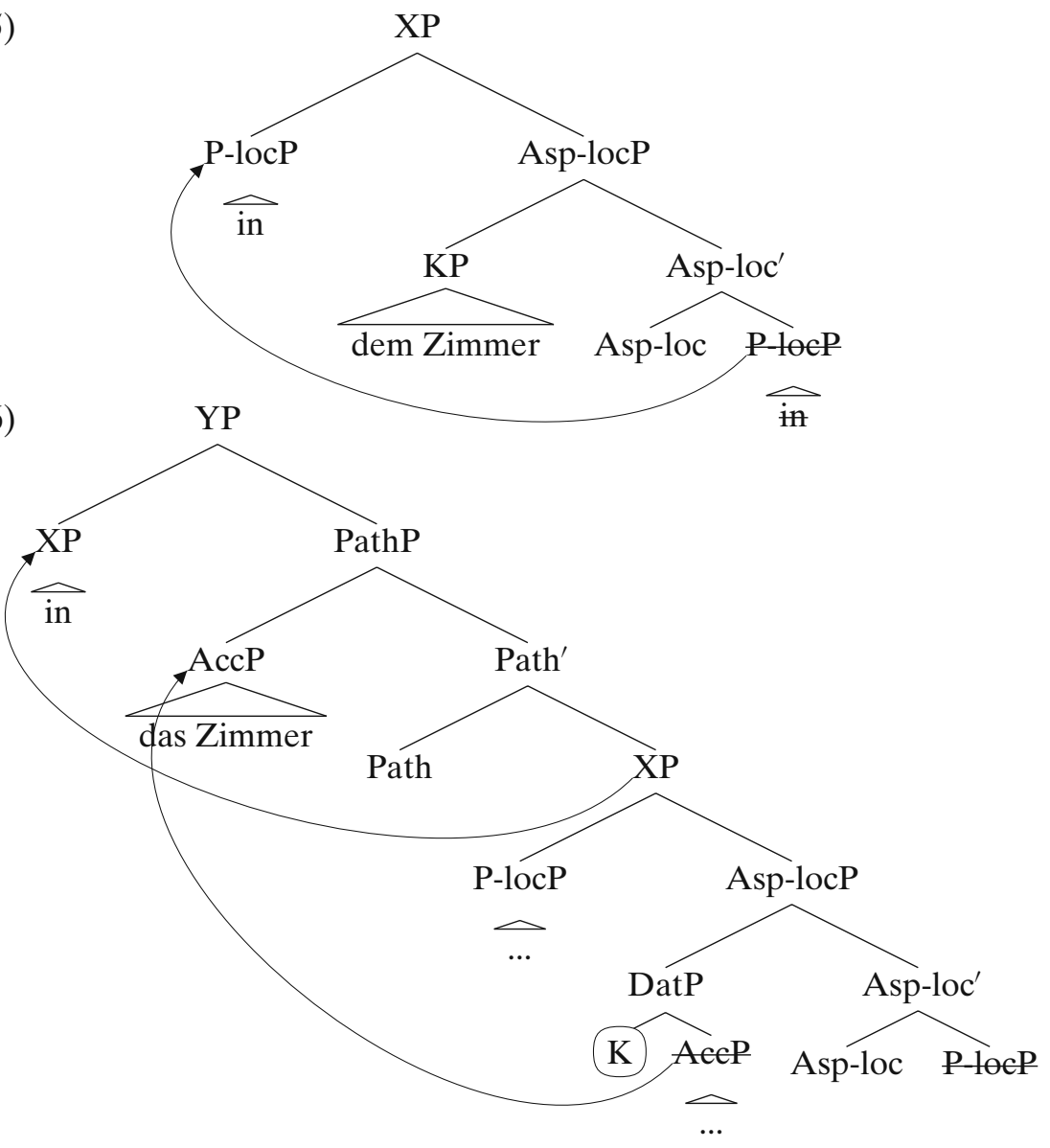

\footnotetext{
${ }^{41}$ The movement of the whole XP may have the following rationale. Apart from sub-extraction, Criterial Freezing also allows for the extended NP in (44) to continue moving from the intermediate position by pied-piping the whole projection of A, a Spec of which YP occupies. Hence, when $\mathrm{P}$-locP moves to Spec,XP, it freezes. To avoid violation of Criterial Freezing when it moves above Path (in German), it must pied-pipe the whole XP.
} 
Under this proposal, the adposition in spells out different nodes in the locative version (P-locP) and in the directional version (XP). I have argued that something along those lines is inevitable. The reason why, in the directional structures, insertion must target XP, rather than P-locP contained inside it, is that only in the former case does lexicalization also target the feature $\mathrm{K}$, contained inside XP. If insertion of the adposition did not target XP, the circled feature $\mathrm{K}$ would remain without a spell out (unless rescued by additional material, if such is available). And that, I propose, would lead to a crash at the PF interface, following the idea of Ramchand (2007) and Fábregas (2007), given in (47), that un-lexicalized features cause a crash at the interface quite generally.

Exhaustive Lexicalisation Principle: Every syntactic feature must be lexicalised. (Fábregas 2007, ex.2)

I now highlight the mechanics of insertion under non-terminal nodes which allows for a unique lexical entry (the adposition in) to find variable constituents for lexicalization in syntax. ${ }^{42}$

\subsection{Lexicalization}

The proposal of the preceding subsection presupposes that insertion happens after syntactic computation (McCawley 1968; Halle and Marantz 1993), and that insertion can target non-terminal nodes, as in McCawley's work. Recently, such an approach has been adopted in Starke (2005), Weerman and EversVermeul (2002) and Neeleman and Szendrói (2007).

The account further presupposes that there is a general condition on insertion different from 'perfect match' between the lexical entry and the syntactic structure, such that the alternating adpositions can be inserted both as locative (P-locP) or directional (XP). The standard approach, based on the Subset Principle, is to assume underspecification of the lexical material with respect to the syntactic structure (see, e.g., Halle 1997 for a classical formulation).

Here, I adopt a similar approach based on the Superset Principle (the proposal going back to Starke 2005). The condition is based on 'overspecification,' but otherwise works quite similarly to the Subset Principle. ${ }^{43}$

The Superset Principle: A phonological exponent is inserted into a node if its lexical entry has a (sub-)constituent that is identical to the node. If there are more such items (with identical encyclopedic information), the one with fewest features not contained in the node gets inserted.

\footnotetext{
${ }^{42}$ These mechanisms have been proposed by Starke (2005), and adapted for various empirical domains in a number of published works, see Caha (2008), Pantcheva (2008), Ramchand (2008), Abels and Muriungi (2008), Muriungi (2008) and Bašić (2007).

${ }^{43}$ The current approach is incompatible with the Subset Principle when it comes to the treatment of non-alternating adpositions.
} 
To illustrate the spell-out system in abstract terms, assume the two lexical entries in (49).
a. $/$ phon $\mathrm{A} / \rightarrow$

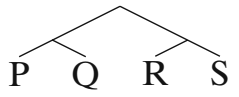
b. $/$ phon $\mathrm{B} / \rightarrow$
$\widehat{\mathrm{P}}$

The entry for /phon A/ can spell out any structure for which the lexical entry contains a perfect match. This means that any of the terminals $(50 \mathrm{a}-\mathrm{d})$, and also the tree structures $(50 \mathrm{e}-\mathrm{g})$ can be lexicalized by the string /phon A/. There is a general requirement that structures like $(50 \mathrm{e}-\mathrm{g})$ are spelled out as a nonterminal if possible, rather than as a sequence of terminals.

The string /phon $\mathrm{B} /$ can lexicalize structures $(50 \mathrm{a}, \mathrm{b}, \mathrm{e})$. In these cases, there are then two candidates for spell out: /phon A/ and /phon B/. Here, the Elsewhere Condition of Kiparsky (1973) — baked into the last sentence of the Superset Principle-takes care that /phon B/ wins over/phon A/: since /phon $\mathrm{B} /$ applies in a proper subset of cases compared to /phon A/, /phon B/takes precedence over/phon A/where both are applicable.
a. $\mathrm{P}$
b. $\mathrm{Q}$
c. $\mathrm{R}$
d. $\mathrm{S}$

e.

f.

g.

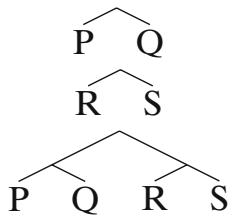

I will further assume, as do Abels and Muriungi (2008), that in each lexical entry, the feature which is lowest in the base-generated functional sequence must be spelled out. I label this the Anchor Condition, since the lowest feature acts as a sort of an anchor of the lexical entry to a particular point in syntax.

The Anchor Condition: In a lexical entry, the feature which is lowest in the functional sequence must be matched against the syntactic structure.

Assuming that $\mathrm{P}, \mathrm{Q}, \mathrm{R}$ and $\mathrm{S}$ in our toy example above are ordered in the base-generated functional sequence as they are in the alphabet ( $\mathrm{P}$ the lowest member), the possibilities of insertion decrease./phon A/ can now only spell out (50a, e, g). (For $(50 \mathrm{a}, \mathrm{e})$, it still loses to /phon B/.) This condition also leads to the consequence (to be returned to) that the lexicalization of some features can only take place if other features have been lexicalized as well. For instance, $\mathrm{Q}$ will never get spelled out unless $\mathrm{P}$ is.

Importantly, traces inside constituents are ignored by the matching procedure. For instance, if QP originates as a complement of $\mathrm{R}$, and $\mathrm{P}$ has a complement in syntax which moves out, as in (52), this does not affect the insertion of /phon A/ under YP in (52). 


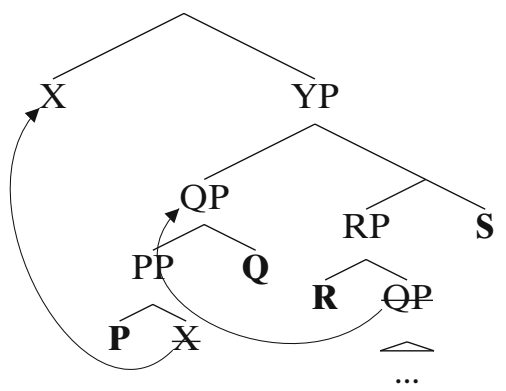

Now we return to adpositions. If the proposal in (45) and (46) is on the right track, alternating adpositions are able to spell out at least P-locP in (45) and XP in (46). Consequently, they are specified as in (53a), where I have used the adposition in for concreteness. According to the Superset Principle, in (and other alternating adpositions) can spell out any (sub-)constituent of their lexical specification, which, according to the Anchor Condition, contains P-loc, the lowest feature in the adpositional functional sequence. The nodes which fulfill these conditions are circled in (53a). Thus, (53a) can be inserted as PlocP in (45), and as XP in (46). The lexical entries are set in such a way that lexicalization of Asp and K presupposes lexicalization of P-loc. ${ }^{44}$

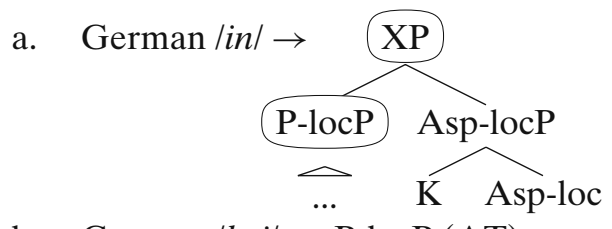

Non-alternating adpositions, like bei 'at', are then specified as P-locP only, see (53b). As a consequence, they cannot lexicalize the whole fronted XP in the directional PP (46), but only a part of it. This in turn means that $\mathrm{K}$ in (46) remains without a spell out, and causes a crash at the (PF) interface.

Can an alternating adposition (53a) spell out the XP in the locative structure (45)? It can't. The reason is that in syntax (45), FP (the accusative) is still contained inside KP, and since the lexical entry (53a) does not make reference to the FP, it does not contain a constituent which matches the XP in (45). Hence, in locative PPs, insertion of in must target P-locP, and $\mathrm{K}$ is spelled out on the DP.

Now consider the two Greek 'in'-s again: locative en (with dative) and directional eis (with accusative). En will have the specification (53b), and eis (53a). This encodes that en (like bei) is locative only, since it cannot spell out the fronted XP in (46). It also encodes that eis can be directional, since it can spell out that XP. But shouldn't eis also be allowed to spell out only P-locP and

\footnotetext{
${ }^{44}$ In the directional structure (46), both Asp-loc and K have a sister: a trace. But these traces are ignored for the purpose of insertion. There is also a trace inside P-locP.
} 
be locative? Here, however, competition comes into play, since both eis and en can spell out P-locP for 'IN'. In this case, en has fewer superfluous features, and wins. As a consequence, $e i$ s will never be locative. ${ }^{45}$

As a last point, consider the adposition $z u$ 'to'. I have argued that the lexical entry of $z u$ 'to' must amalgamate both P-loc and Path, as in (54).

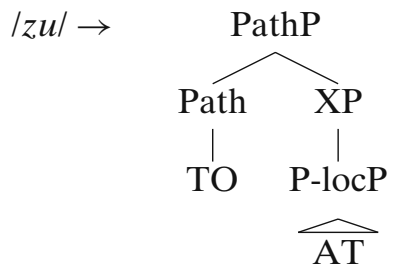

Note first that $z u$ can (in principle) be inserted either as PathP or as P-locP. ${ }^{46}$ In the latter case, it would act as a locative adposition, which is not the case (most of the time). The reason why $z u$ does not act as a locative adposition is that in the locative context (P-locP), it loses in competition to bei, see (53b). However, recall here from footnote 8 that $z u$ does have some locative uses. These can be accounted for by proposing that while bei and $z u$ conceptually overlap, they do differ a little. In cases where $z u$ appears in a locative guise, we can say that bei cannot be inserted, because its conceptual content is not appropriate. This takes bei out of competition, and allows $z u$ to lexicalize PlocP.

Now consider the syntactic structure for $z u$ 'to' derived by the mechanisms I have proposed so far:

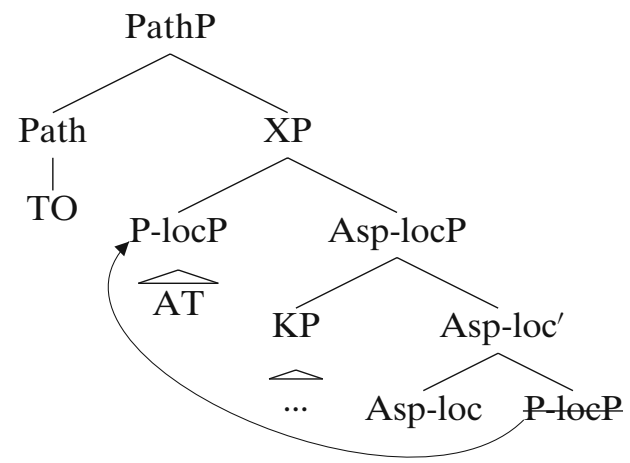

\footnotetext{
${ }^{45}$ Note in passing that eis is a strictly directional adposition, which—unlike $z u$-assigns accusative. The strict directionality of eis is not, however, caused by its insertion under Path, but rather by the fact that for the locative structure, eis loses in competition. This reasoning can be extended to also cover the German durch 'through = VIA IN', which assigns accusative, despite the fact that it is strictly directional. Similarly the Dutch strictly directional postposition $a f$ 'off $=$ FROM ON' receives such an analysis in Caha (2007a).

${ }^{46} \mathrm{As}$ far as insertion as XP is concerned, it will never become relevant. In locatives, XP contains other material, and so insertion under XP is out of question. As we will see shortly, both XP and PathP are suitable targets in directionals. However, since spell out of bigger chunks is preferred, insertion under XP does not take place here either.
} 
The problem is that our spell-out procedure does not allow for the insertion of (54) at PathP in (55). That is because PathP in (55) also contains Asp-loc and the dative KP, and so (54) does not have an identical sub-constituent. We need to perform two movements: extract Asp-locP from within PathP (to obtain a match between $z u$ in (54) and the PathP in (55)), and then move PathP higher up again (to get the word order right for $z u$ ). After these movements, both the dative $\mathrm{DP}$ and $[\mathrm{TO}+\mathrm{AT}]$ form separate constituents, subject to insertion.

The movement of PathP can be assumed to target the same position to which $\mathrm{P}$-locP moves quite generally. In the regular instance, it pied-pipes only XP (due to the fact that it cannot move alone by Criterial Freezing), but in this case, it pied-pipes a larger constituent.

The motivation for the evacuation of Asp-locP out of PathP remains a topic for future research. I wish to note here, though, that the movement creates a stage in the derivation where a strictly directional adposition with dative is a postposition. The existence of such a stage seems confirmed by instances of strictly directional nach 'to' acting as a postposition (see footnote 6), and (possibly spurious) instances of postpositional entgegen 'against' (see footnote 9), both of which take dative.

\subsection{Interim summary: the structure of the Peeling Theory}

Let me recapitulate the core principles of Peeling:
The structure of the Peeling Theory
a. Case decomposition: [ Dat [ Acc ] ]
b. Criterial Freezing:
DPs move by sub-extraction
c. Lexicalization:
Layers shed by DPs must be spelled out

The core predictions this theory makes are the result of the interaction of (56a) and (56b). In particular, the theory can derive the change from dative to accusative, but it cannot derive the reverse alternation: a change from an accusative into a dative. As far as I can tell, this is a good prediction. Of course, I cannot do justice to the whole range of predictions and potential counterexamples here. ${ }^{47}$

The source of (56a) is independent of Peeling: it is not the case that we first see which case changes into which case, and construe the functional sequence accordingly-although even the very existence of such a hierarchy of case shifting would be a fact worth of serious attention. Here, the empirical bite is even stronger: the universal functional sequence arises from independent considerations, like the ones mentioned in Section 8.1, and case shifting must obey this functional sequence. The slogan is: the higher you go, the smaller you get.

\footnotetext{
${ }^{47}$ An anonymous reviewer suggests that certain instances of differential object marking might be problematic for this view. I cannot discuss this here for reasons of space, but I think that a Peeling consistent account can be given here too. Relevant here is the work of Nilsen (2003), who reverses the traditional perspective on movement of definite/specific and indefinite/non-specific objects.
} 
After sub-extraction, case shells no longer form a constituent with the DP, and they turn into heads spread along the path of movement. These heads become a part of the category in whose projection the extended NP moves. This is achieved by lexicalization which targets larger chunks of structure. ${ }^{48}$

This ingredient of the Peeling Theory (56c) serves as a 'restrictor.' Case shifting is not always possible; there are idiosyncrasies pertaining to particular items, constructions, or languages. These restrictions must be stated somewhere, and the lexicon seems to be a natural place for them. In fact, if the lexicon is the place where (micro-)parameters live, this might well be the only place available. Note though that lexicalization is restricted to constituents, and it can only spell out chunks of structure which syntax independently generates.

\section{Passives}

The last remaining issue is to see if the Peeling Theory offers a solution to the Problem of the Oblique. The question is why dative cannot be promoted to a structural case in be-passives, given that it can do so in PPs.

\subsection{Promotion of the accusative}

A preliminary step of the analysis is to find a place for the nominative case in our partial functional sequence. Neeleman and Weerman (1999, ch.3) gather empirical arguments for the proposal that nominative lacks a functional head present with accusative. Here, I have called this head F; below I show that F attaches on top of nominative.

$$
\text { [Dative } \mathrm{K} \text { [Accusative F [ Nominative ] ] ] }
$$

With (57) in place, consider a possible analysis of direct object promotion in passive. The first step that concerns us brings an internal argument to the direct object (accusative) position. In the active sentence, it stays there, because the nominative position is swallowed by the external argument. In passive, however, the nominative position is vacant due to the demotion of the external

\footnotetext{
${ }^{48}$ Two anonymous reviewers point out that this sounds like a conspiracy: what gets stranded is case, but we never see the actual stranded morpheme (i). However, compare a similar case of ellipsis (ii), suggesting that the disappearence of case morphemes might be due to other reasons as well.

The situation is also not black-and-white. For instance, applicative morphemes are often identical to, or historically derived from, affixes marking obliques. This can be understood if applicative morphemes are the spell out of stranded case shells, from which the applied argument has sub-extracted.
}

(i) I gave [him] the book (*to [him]).

(ii) Since John was busy, I went there instead (*of). 
argument (or a failure of its promotion, as in Collins 2005). Consequently, the nominative contained inside the internal argument is free to sub-extract from inside the accusative (58).

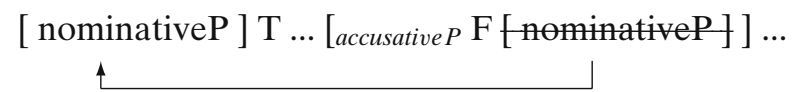

Assuming that there is a unique nominative position in the clause which must be filled, this approach captures the insight of Marantz (1991) and subsequent work that the assignment of accusative is 'dependent' on the presence of a higher argument. That is because the internal argument will only stay in the accusative position if the nominative position is blocked by the higher argument (or absent altogether); otherwise the nominative obligatorily subextracts. However, while in Marantz (1991) the dependent status of accusative is stated outside of the core syntax (as a sort of a mapping rule), here we account for the dependent status by the mechanisms of syntax alone.

The present approach to passive differs from most alternatives in proposing that the internal argument occupies the accusative position at some stage of the derivation. The existence of such an accusative stage in the life of the internal argument is supported by case marking patterns in Ukrainian passives (59). Here the internal argument can surface either as nominative (59a), or accusative (59b) (the difference is accompanied by the presence/absence of agreement on the optional copula and the participle). The latter example can be analyzed under the present proposal as a result of the failure of the internal argument to raise to the nominative position. ${ }^{49}$
a. Cerkv-a (bula) zbudova-na v 1640 roci (Lesevym). church-NOM was.FEM build-PASS.FEM in 1640 year Lesiv-INS 'The church was built in 1640 by Lesiv.'
b. Cerkv-u (bulo) zbudova-no v 1640 roci (Lesevym). church-ACC was build-PASS in 1640 year Lesiv-INS 'There was built a church in 1640 by Lesiv.'

(Ukrainian, Sobin 1985:653,658)

Turning back to the derivation in (58), the requirement is that the feature $\mathrm{F}$ stranded by the movement must be spelled out. There are two candidates for the job: the passive -en (cf. the traditional conception of -en as 'absorbing' the accusative case), or the auxiliary be. I won't dwell much on the issue, and I am going to assume the traditional approach under which $F$ is spelled out as a part of the passive -en. With respect to the issue of what the passive morpheme is doing in (59b), recall that under the Superset Principle driven insertion, there

\footnotetext{
${ }^{49}$ It is not clear (to me) why Ukrainian allows the internal argument to stay in the direct object position, while most languages force obligatory movement to the nominative position.
} 
is no necessity for the stranded $\mathrm{F}$ to be present in order for the equivalent of -en to be inserted, as long as there are other features for -en to spell out. Hence, there is no one-to-one correspondence between the absorption of accusative and the appearance of -en.

\subsection{Promotion of the dative}

For dative passives, I propose a derivation which begins with the indirect object landing in the dative position (or being base-generated there). In order to become nominative, the indirect object has to strand both $\mathrm{K}$ and $\mathrm{F}$; there are two possible ways this can happen. One, the indirect object first strands the K shell and lands in an accusative position, which is followed by another step of movement that strands $\mathrm{F}$ in the intermediate position (60). Alternatively, both shells are dumped at once (61). The first approach appears more plausible, since at least in ECM contexts, an accusative position must be available for a passivized indirect object, and so I adopt (60) here.

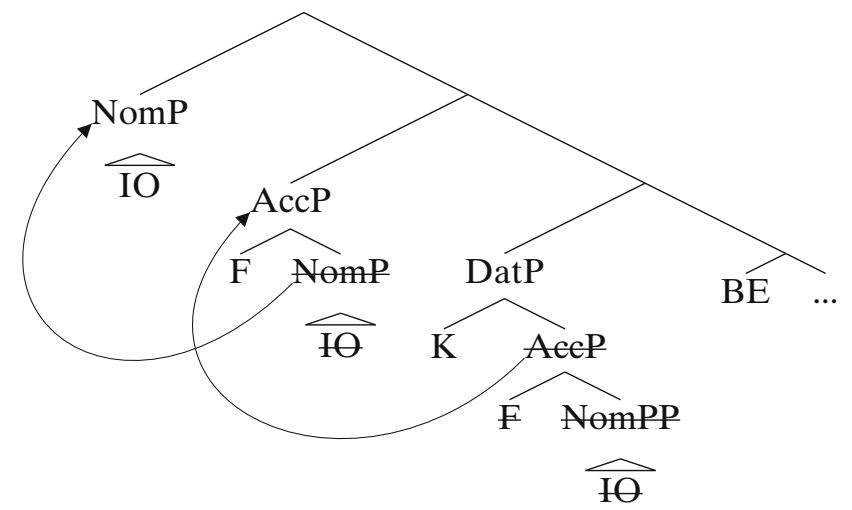

(61)

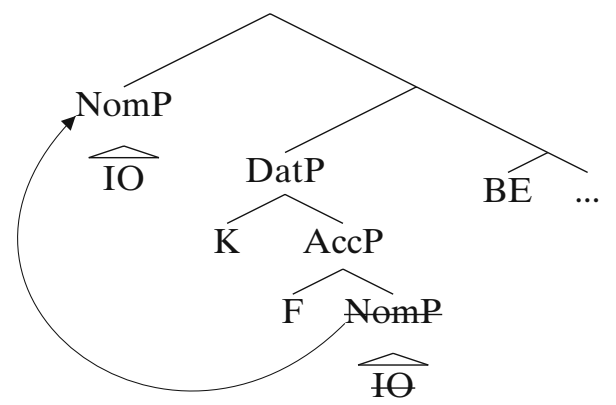

Two questions arise. One, why can't the accusative position be accessed by the indirect object in the active sentence (leading to two accusative objects)? Two, doesn't this prevent the direct object from becoming accusative?

The answer to both questions is that the accusative position through which the indirect object moves is a position which, in the active sentence, is used up by the external argument on its way from an oblique to nominative; it is a 
low 'subject' position. ${ }^{50}$ This also means that the shell $\mathrm{F}$ is disposed of in the same way as subject shells in general, and it does not require special attention in connection with passives.

The left-over $\mathrm{K}$ in (60), however, must be spelled out, as is familiar by now. I propose that neither the copula 'be' nor the participle ending are fit for the job (in German); some other lexical item must kick in. This brings our attention to a construction in German in which a subset of dative arguments can be promoted to nominative, provided that the passive participle is embedded under one of the two verbs bekommen or kriegen 'get'. An example is given below (62). The DP 'the patient', originally in the dative (62a), is promoted to nominative in (62b), in which case the auxiliary is 'get'.

a. Der Chirurg entfernte dem Patienten die Milz.
the.Nom surgeon removed the.DAT patient the.ACC spleen
b. Der Patient bekam / kriegte die Milz entfernt.
the.Nom patient got / got the.ACC spleen removed

(Bayer et al. 2001, ftn.1)

The derivation of (62b) is depicted in (60). The idea is that either of the two auxiliaries, both meaning 'get', spells out the leftover shell K (63). In this property (possibly among others), the verbs differ from werden 'be'. The proposal neatly captures the facts. First, dative can be promoted to nominative, and second, in case this happens, the auxiliary must shift from werden to bekommen/kriegen. This approach sees these two facts as related: the auxiliary shift occurs as a consequence of the case shift. ${ }^{51,} 52$

\footnotetext{
${ }^{50}$ See Caha (2007b), where it is proposed that the subject is born as a by-phrase, and it moves to the nominative position via an intermediate accusative position, first by stranding by and only then the accusative shell.

The existence of an intermediate landing site is required for subjects also in a theory which derives floating quantifiers by stranding, e.g., Sportiche (1988) and Bošković (2004a). First, subjects can float quantifiers. Second, floating in the base position is ruled out. Hence, the subject must move through an intermediate position on its way to nominative.

${ }^{51}$ Such an approach takes inspiration in proposals by Freeze (1992) or Kayne (1993) who see the difference between be and have in similar terms; specifically, have = be plus an incorporated preposition. Here, get is seen as be with 'incorporated' dative $\mathrm{K}$. The same analysis is pursued by Taraldsen (2008) for comparable facts in Norwegian and Swedish.

${ }^{52}$ Note the lexical entries for 'get' (63) and 'be' (64): 'be' [BE] is properly contained in 'get' $[\mathrm{BE}+\mathrm{K}]$. This entails (by the Superset Principle) that there is a competition for insertion: the node BE can be spelled out by both. In German, 'be' wins in competition. Now if the only reason why 'get' does not occur in accusative passives is competition, we have a prediction: if the entry for BE (64) did not exist in the lexicon, a single morpheme 'get-be' would occur both in dative and accusative passives. This prediction is supported by data from Japanese.

Japanese, like German, allows the promotion of dative arguments to nominative (ia, b). The verb is suffixed by a passive morpheme (r)are in (ib), and the same morpheme appears on the verb also in case the accusative object is promoted to nominative (ic).
}

(i) a. Naomi-ga Ken-ni labuletaa-o watasi-ta.

Naomi-NOM Ken-DAT loveletter-ACC hand-PAST

'Naomi gave a love letter to Ken.' 


$$
\text { |kriegen, bekommen/ } \Rightarrow[\mathrm{K}[\mathrm{BE}]]
$$

$$
\text { /werden/ } \Rightarrow[\mathrm{BE}]
$$

Such a proposal is neither uncontroversial, nor unprecedented. Some researchers have argued that 'get' is indeed an auxiliary that enables the passivization of the dative (e.g., Reis 1985; Fanselow 2000; Anagnostopoulou 2003:ch.3), but an alternative analysis exists. It claims that 'get' is a kind of light verb with its own argument structure, which is combined with the argument structure of the participle via $\theta$-role identification (e.g., Haider 2001; Cook 2006).

I believe that the passive analysis is correct, and I give two reasons for that. First, it has been pointed out that in certain contexts, the verb 'get' does not assign a $\theta$-role to its subject, since the subject does not actually get anything (65). Hence, the interpretation of the nominative is thematically linked only to the participle.
a. Er bekam zwei Zähne ausgeschlagen. he got two teeth knocked out
b. Der Bub kriegt das Spielzeug weggenommen. the lad gets the toy taken away

(Cook 2006, ex.11)

In the same vein, datives which are interpreted idiomatically allow promotion to nominative in get-passives. The idiomatic reading of (66a) is preserved in (66b); granted the assumption that idiomatic reading is assigned to constituents, the nominative in (66b) must have formed a constituent with the participle at the beginning of the derivation. Further, not only does the DP originate downstairs, it also cannot receive a thematic role from 'get', otherwise the idiomatic interpretation would be blocked.

(66) a. der Katze die Schelle umhängen

the cat.DAT the bell.ACC around.hang

'lit. hang a bell on the cat, idiom. do something unpleasant to others'

b. Und von wem kriegt die Katze die Schelle umgehängt? and from who got the cat.NOM the bell around.hanged 'Who was doing something unpleasant to others?'

(Reis 1985, ex.31)

b. Ken-ga Naomi-ni labuletaa-o watas-are-ta. Ken-NOM Naomi-DAT love letter-ACC hand-PASS-PAST

'Ken was given a love letter by Naomi.'

(Japanese, Kazenin 2001:902)

c. Labuletaa-ga Ken-ni watas-are-ta.

love letter-NOM Ken-DAT hand-PASS-PAST

'The love letter was given to Ken.'

(Japanese, Kaori Takamine, p.c.) 
To conclude: I have tried to unify conditions on oblique to structural case alternations in PPs and VPs. The unifying idea is that in both instances, case shifting is possible provided that the stranded $\mathrm{K}$ is spelled out.

\section{Conclusions}

In this paper, I have argued that in German directional PPs with accusative, the DP passes through two case positions: Asp-loc and Asp-dir. This provided a solution to the Missing Assigner problem and allowed for an approach to $z u$ as the spell out of [TO+AT]. Apart from that, the derivations found direct support in certain facts concerning temporal PPs in German, and the Dutch locative-directional alternation.

I have developed an implementation of the alternation in terms of the Peeling Theory of case (Starke 2005), in which DPs are born with multiple case shells, and strand them as they move up in the tree. This has proved a useful strategy in accounting for the fact that not all adpositions alternate, the idea being that a stranded Peel must be spelled out. The same mechanics led to an account of the fact that in German, a dative argument can be promoted to nominative in passive, provided the auxiliary is 'get' and not 'be'.

On a more general level, these ideas lead to a different interpretation of the phenomenon of case than standardly assumed. Chomsky (1998) and related work consider case (together with agreement) to be a specific type of syntactic object, an uninterpretable feature in need of valuation. Here, I have followed a different line of thinking, and regarded case to be an ordinary type of object, a set of functional projections, with each case a unique collection of such projections. Consequently, the traditional conception of licensing by case marking, coded by the notion of uninterpretable feature, is altogether absent in the present theory. Here, DPs are equipped with case layers from the very beginning, and they shed these layers by moving upwards in the tree.

The specific prediction of this approach is that an oblique case can change to a structural case, but not the other way round. Within the structural cases, accusative can change to nominative, but the reverse alternation is ruled out. This follows from the interaction of two independent proposals: the functional sequence, and Criterial Freezing.

Last but not least, I have used the idea (see, e.g., Chomsky 1995) that movement and case are correlated in an interesting way.

Acknowledgements I am grateful to the following people for feedback concerning various aspects of the present paper: Marcel den Dikken, Marina Pantcheva, Gillian Ramchand, Michal Starke and Peter Svenonius. I would like to thank my informants who provided me with data and judgments: Klaus Abels, Martin Krämer, Kaori Takamine, Christian Uffman and Marleen van de Vate. Special thanks to Marina Pantcheva for carefully reading and commenting on various final versions of this paper. Thanks also to all the participants of the Peeling lab in Troms $\varnothing$ in Spring 2008, and to the audiences at CGSW 23, and CASTL Colloquium in Troms $\varnothing$, where parts of this paper were presented. 
The present version of the paper has greatly benefited from interesting comments, suggestions, observations and criticism by five anonymous JCGL reviewers; I thank them all. One of the reviewers later became 'onymous,' and so I can thank Berit Gehrke in person. I also thank the editor of JCGL, Henk van Riemsdijk, for his comments on a previous version of this paper, and his advice concerning the revision process.

Open Access This article is distributed under the terms of the Creative Commons Attribution Noncommercial License which permits any noncommercial use, distribution, and reproduction in any medium, provided the original author(s) and source are credited.

\section{References}

Abels, Klaus. 2003. Successive cyclicity, anti-locality, and adposition stranding. PhD thesis, University of Connecticut, Storrs.

Abels, Klaus, and Peter K. Muriungi. 2008. The focus particle in Kîitharaka: Syntax and semantics. Lingua 118:687-731.

Anagnostopoulou, Elena. 2003. The syntax of ditransitives. Evidence from clitics. Berlin, New York: Mouton de Gruyter.

Baker, Mark C. 1988. Incorporation: A theory of grammatical function changing. Chicago: University of Chicago Press.

Bašić, Monika. 2007. Serbian Ps with and without iz and the Superset Principle. In Nordlyd 34.2: Special issue on space, motion, and result, eds. Monika Bašić, Marina Pantcheva, Minjeong Son, and Peter Svenonius, 300-319. Troms $\emptyset$ : University of Troms $\varnothing$. Available at www.ub.uit. no/munin/nordlyd/.

Bayer, Joseph, Markus Bader, and Michael Meng. 2001. Morphological underspecification meets oblique case: Syntactic and processing effects in German. Lingua 111:465-514.

Bejar, Susana, and Diane Massam. 1999. Multiple case checking. Syntax 2:65-79.

Blake, Barry J. 1994. Case (2nd ed.). Cambridge: Cambridge University Press.

Bošković, Željko. 2004a. Be careful where you float your quantifiers. Natural Language and Linguistic Theory 22:681-742.

Bošković, Željko. 2004b. Object shift and the clause/PP parallelism hypothesis. In WCCFL 23 proceedings, eds. B. Schmeiser, V. Chand, A. Kelleher, and A. Rodriguez, 101-114. Somerville: Cascadilla Press.

Caha, Pavel. 2007a. Case movement in PPs. In Nordlyd 34.2: Special issue on space, motion, and result, eds. Monika Bašić, Marina Pantcheva, Minjeong Son, and Peter Svenonius, 239-299. Troms $\varnothing$ : University of Troms $\emptyset$. Available at: www.ub.uit.no/munin/nordlyd/.

Caha, Pavel. 2007b. A note about a note about nothing. In Czech in generative grammar, eds. Mojmír Dočekal, Markéta Ziková, and Jana Zmrzlíková, 17-30. München: LINCOM.

Caha, Pavel. 2008. The case hierarchy as functional sequence. In Scales (no. 86 in Linguistische Arbeits Berichte), eds. Marc Richards and Andrej L. Malchukov, 247-276. Leipzig: University of Leipzig.

Caha, Pavel. 2009. The nanosyntax of case. PhD thesis, CASTL, University of Troms $\emptyset$.

Chomsky, Noam. 1995. The minimalist program. Cambridge, MA: MIT Press.

Chomsky, Noam. 1998. Minimalist inquiries: The framework. MIT Occasional Papers in Linguistics 15:1-56.

Cinque, Guglielmo. 2005. Deriving Greenberg's universal 20 and its exceptions. Linguistic Inquiry 36:315-332.

Collins, Chris. 2005. A smuggling approach to the passive in English. Syntax 8:81-120.

Cook, Philippa. 2006. The datives that aren't born equal: Beneficiaries and the dative passive. In Datives and other cases. Between argument structure and event structure (no. 75 in Studies in Language Companion Series), eds. Daniel Hole, André Meinunger, and Werner Abraham, 141-184. Amsterdam: John Benjamins.

den Dikken, Marcel. 2003. On the syntax of locative and directional adpositional phrases. Ms. City University of New York. 
den Dikken, Marcel. 2010. On the functional structure of locative and directional PPs. In The cartography of syntactic structure, Vol. 6, eds. Guglielmo Cinque and Luigi Rizzi, 74-126. New York: Oxford University Press.

Emonds, Joseph. 2007. Czech cases and the Syntacticon: Poznámky k, o, okolo, nad něčím a pro někoho. In Czech in generative grammar, eds. Mojmír Dočekal, Markéta Ziková, and Jana Zmrzlíková, 81-104. München: LINCOM.

Fábregas, Antonio. 2007. An exhaustive lexicalisation account of directional complements. In Nordlyd, special issue on space, motion, and result (no. 34.2 in Troms $\varnothing$ Working Papers on Language and Linguistics), eds. Monika Bašić, Marina Pantcheva, Minjeong Son, and Peter Svenonius, 165-199. Troms $\varnothing$ : CASTL, University of Troms $\emptyset$.

Fanselow, Gisbert. 2000. Optimal exceptions. In The Lexicon in Focus (no. 45 in Studia Grammatica), eds. Barbara Stiebels and Dieter Wunderlich, 173-209. Berlin: Akademie Verlag.

Fong, Vivienne. 1997. The order of things: What directional locatives denote. PhD thesis, Stanford University.

Freeze, Ray. 1992. Existentials and other locatives. Language 68.3:553-595.

Gehrke, Berit. 2007. On directional readings of locative adpositions. In Proceedings of ConSole $X I V$, eds. Sylvia Blaho, Luis Vicente, and Erik Schoorlemmer, 99-120. Leiden: Universiteit Leiden.

Gehrke, Berit. 2008. Ps in motion. PhD thesis, University of Utrecht.

Haider, Hubert. 2001. Heads and selection. In Semi-lexical categories: The function of content words and the content (no. 59 in Studies in Generative Grammar), eds. Norbert Corver and Henk van Riemsdijk, 67-96. Berlin and New York: Mouton de Gruyter.

Hale, William Gardner, and Carl Darling Buck. 1903. A Latin grammar. Boston and London: Ginn and Co.

Halle, Morris. 1997 Impoverishment and fission. In Papers at the interface (no. 30 in MITWPL), eds. Benjamin Bruening, Y. Kang, and Martha McGinnis, 425-449. Cambridge, MA: MIT.

Halle, Morris, and Alec Marantz. 1993. Distributed morphology and the pieces of inflection. In The view from building 20: Essays in linguistics in honor of Sylvain Bromberger, eds. Kenneth Hale and Samuel Jay Keyser, 111-176. Cambridge, MA: MIT Press.

Haspelmath, Martin. 1997. From space to time. München: LINCOM.

Helmantel, Marjon. 2002. Interactions in the Dutch adpositional domain. PhD thesis, Leiden.

Hróarsdóttir, Thorbjörg. 2000. Parameter change in Icelandic. In The derivation of VO and OV, ed. Peter Svenonius, 153-179. Amsterdam: John Benjamins.

Jackendoff, Ray. 1983. Semantics and cognition. Cambridge, MA: MIT Press.

Kayne, Richard S. 1993. Toward a modular theory of auxiliary selection. Studia Linguistica 47(1):3-31.

Kayne, Richard S. 1998. Overt vs. covert movement. Syntax 1:128-191.

Kayne, Richard S. 2004. Here and there. In Lexique, Syntaxe et Lexique-Grammaire/Syntax, Lexis \& Lexicon-Grammar: Papers in Honor of Maurice Gross, eds. C. Leclère, E. Laporte, M. Piot, and M. Silberztein, 253-275. Amsterdam: John Benjamins.

Kazenin, Konstantin. 2001. The passive voice. In Language typology and language universlas, eds. Martin Haspelmath, Ekkehard Konig, Wulf Oesterreicher, and Wolfgang Raible, 899-916. New York: Walter de Gruyter.

Kiparsky, Paul. 1973. 'Elsewhere' in phonology. In A Festschrift for Morris Halle, eds. Paul Kiparsky and Steven Anderson. New York: Holt, Rinehart and Winston.

Koopman, Hilda. 1996. The spec head configuration. In Syntax at sunset, eds. Edward Garrett and Felicia Lee, 37-64. Los Angeles: Department of Linguistics, UCLA.

Koopman, Hilda. 2000. Prepositions, postpositions, circumpositions, and particles. In The syntax of specifiers and heads, ed. Hilda Koopman, 204-260. London: Routledge.

Krause, Todd, and Jonathan Slocum. 2010. Tocharian online. http://www.utexas.edu/cola/centers/ lrc/eieol/tokol-0.html.

Krause, Wolfgang, and Thomas Werner. 1960. Tocharisches Elementarbuch. Band I: Grammatik. Heidelberg: Carl Winter.

Levinson, Stephen C. 2003. Space in language and cognition: Explorations in cognitive diversity. Cambridge: Cambridge University Press.

Luraghi, Silvia. 2003. On the meaning of prepositions and cases: The expression of semantic roles in Ancient Greek. Amsterdam: John Benjamins. 
Marantz, Alec. 1991. Case and licensing. In Proceedings of the Eastern States conference on linguistics, Vol. 8, 234-253. Cambridge, MA: MIT.

McCawley, James D. 1968. Lexical insertion in a transformational grammar without Deep Structure. In Papers from the fourth regional meeting of the Chicago Linguistic Society, eds. B.J. Darden, C.-J.N. Bailey, and A. Davidson. Chicago: University of Chicago.

McFadden, Thomas. 2004. The position of morphological case in the derivation: A study on the syntax-morphology interface. $\mathrm{PhD}$ thesis, University of Pennsylvania.

Medová, Lucie. 2008. Reflexive clitics in Slavic and Romance. PhD thesis, Princeton University.

Medová, Lucie, and Tarald Taraldsen. 2007. 1, 2, SE. In Czech in generative grammar, eds. Mojmír Dočekal, Markéta Ziková, and Jana Zmrzlíková, 119-138. München: LINCOM.

Merchant, Jason. 2006. Polyvalent case, geometric hierarchies, and split ergativity. In Proceedings of the 42nd annual meeting of the Chicago Linguistics Society, eds. Jackie Bunting, Sapna Desai, Robert Peachey, Chris Straughn, and Zuzana Tomkova. Chicago: University of Chicago.

Muriungi, Peter. 2008. Phrasal movement inside Bantu verbs: Deriving affix scope and order in kiitharaka. $\mathrm{PhD}$ thesis, CASTL, Troms $\varnothing$.

Neeleman, Ad, and Kriszta Szendrói. 2007. Radical pro-drop and the morphology of pronouns. Linguistic Inquiry 38:671-714.

Neeleman, Ad, and Fred Weerman. 1999. Flexible syntax: A theory of case and arguments. Dordrecht: Kluwer Academic Publishers.

Nilsen, Øystein. 2003. Eliminating positions: Syntax and semantics of sentential modification. $\mathrm{PhD}$ thesis, Universiteit Utrecht, Utrecht.

Noonan, Máire. 2007. À to zu. Handout 3 of a course taught at EGG07, Brno.

Pantcheva, Marina. 2008. The syntactic structure of locations, goals, and sources. Ms., University of Troms $\varnothing$, downloadable as http://ling.auf.net/lingBuzz/000763.

Pesetsky, David. 2007. Undermerge... and the secret genitive inside every Russian noun. Handout of a talk at FASL 16.

Postal, Paul Martin. 1974. On raising: One rule of English grammar and its theoretical implications. Current studies in linguistics series 5. Cambridge, MA: MIT Press.

Ramchand, Gillian. 2007. Selection, conflation and denominal verbs. Ms., University of Troms $\emptyset$. Talk at the University of Basque Country.

Ramchand, Gillian. 2008. Verb meaning and the Lexicon. Cambridge: Cambridge University Press.

Reis, Marga. 1985. Mona Lisa kriegt zuviel—vom sogenannten 'Rezipientpassiv' im Deutschen. Linguistische Berichte 96:140-155.

Richards, Norvin. 2007. Lardil "case stacking" and the structural/inherent case distinction. Ms., MIT, downloadable at: http://ling.auf.net/lingBuzz/000405.

Rizzi, Luigi. 2004. On the form of chains: Criterial positions and ECP effects. Ms., University of Siena.

Schmitt, Rüdiger. 1981. Grammatik des Klassisch-Armenischen. No. 32 in Innsbrucker Beiträge zur Sprachwissenschaft. Innsbruck: Institut für Sprachwissenschaft der Universität Innsbruck.

Smyth, Herbert Weir. 1974. Greek grammar. Cambridge, MA: Harvard University Press.

Sobin, Nicholas J. 1985. Case assignment in Ukrainian morphological passive constructions. Linguistic Inquiry 16.4:649-672.

Sportiche, Dominique. 1988. A theory of floating quantifiers and its corollaries for constituent structure. Linguistic Inquiry 19(3):425-449.

Starke, Michal. 2004. On the inexistence of specifiers and the nature of heads. In Structures and beyond: The cartography of syntactic structures, Vol. 3, ed. Adriana Belletti, 252-268. New York: Oxford University Press.

Starke, Michal. 2005. Nanosyntax class lectures. Spring 2005. University of Troms $\varnothing$.

Svenonius, Peter. 2002. Icelandic case and the structure of events. Journal of Comparative Germanic Linguistics 5:197-225.

Svenonius, Peter. 2010a. Case alternations in the Icelandic passive. In Passives and impersonals in European languages, eds. Satu Manninen, Diane Nelson, Katrin Hiietam, Elsi Kaiser, and Virve Vihman. Amsterdam: John Benjamins (to appear).

Svenonius, Peter. 2010b. Spatial P in English. In The cartography of syntactic structure, Vol. 6, eds. Guglielmo Cinque and Luigi Rizzi, 127-160. Oxford: Oxford University Press. Available at http://ling.auf.net/lingBuzz/000001.

Taraldsen, Tarald. 2000. V-movement and VP-movement in derivations leading to VO-order. In The derivation of $V O$ and $O V$, ed. Peter Svenonius, 97-122. Amsterdam: John Benjamins. 
Taraldsen, Tarald. 2008. Unintentionally out of control. Ms., CASTL, University of Troms $\emptyset$.

Taraldsen, Tarald, and Lucie Medová. 2007. The Czech locative chameleon. In Nordlyd 34.2: Special issue on space, motion, and result, eds. Monika Bašić, Marina Pantcheva, Minjeong Son, and Peter Svenonius, 239-299. Troms $\varnothing$ : University of Troms $\varnothing$. Available at: www.ub.uit.no/ munin/nordlyd/.

Tungseth, Mai Ellin. 2008. Verbal prepositions and argument structure: Path, place and possession in Norwegian. Linguistik Aktuell/Linguistics Today 121. Amsterdam: John Benjamins.

van Riemsdijk, Henk. 1978. A case study in syntactic markedness: The binding nature of prepositional phrases (2nd ed.). Dordrecht: Foris.

van Riemsdijk, Henk. 1990. Functional prepositions. In Unity in diversity, eds. H. Pinkster and I. Gene, 229-241. Dordrecht: Foris.

van Riemsdijk, Henk. 2007. Case in spatial adpositional phrases: The dative-accusative alternation in German. In Pitar Mos: A building with a view. Festschrift for Alexandra Cornilescu, eds. Gabriela Alboiu, Andrei Avram, Larisa Avram, and Isac Dana, 1-23. Bucharest: Bucharest University Press.

van Riemsdijk, Henk, and Riny Huybregts. 2002. Location and locality. In Progress in grammar: Articles at the 20th anniversary of the comparison of grammatical models group in Tilburg, eds. Marc van Oostendorp and Anagnostopoulou Elena, 1-23. Amsterdam: Meertens Instituut. www.meertens.knaw.nl/books/progressingrammar/.

Weerman, Fred, and Jacqueline Evers-Vermeul. 2002. Pronouns and case. Lingua 112:301-338

Woolford, Ellen. 2006. Lexical case, inherent case, and argument structure. Linguistic Inquiry 37:111-130.

Zwarts, Joost. 2005. The case of prepositions: Government and compositionality in German PPs. Paper presented at the 21st annual meeting of the Israel Association for Theoretical Linguistics, Haifa, June 23. Downloadable at: http://www.let.uu.nl/users/Joost.Zwarts/personal/ Papers/CofPs.pdf.

Zwarts, Joost. 2006. Case marking direction: The accusative in German PPs. Paper presented at the 42rd meeting of the Chicago Linguistic Society, Chicago, April 7. Downloadable at: http:// www.let.uu.nl/users/Joost.Zwarts/personal/Papers/CLS.pdf.

Zwarts, Joost. 2008. Encoding spatial direction: The role of case, lexicon and word order. Paper presented at the Workshop on Locative Case, Nijmegen, August 2008.

Zwarts, Joost, and Yoad Winter. 2000. Vector space semantics: A model-theoretic analysis of locative prepositions. Journal of Logic, Language, and Information 9:169-211. 